\title{
Primary Mutational Landscape Linked with Pre-docetaxel Lactate Dehydrogenase Levels Predicts Docetaxel Response in Metastatic Castrate-resistant Prostate Cancer
} DOI:

10.1016/j.euf.2018.04.006

\section{Document Version \\ Accepted author manuscript}

Link to publication record in Manchester Research Explorer

Citation for published version (APA):

Hiew, K., Hart, C., Ali, S. A., Elliott, T., Ramani, VAC., Sangar, V., Lau, M., Maddineni, S. B., Brown, M., \& Clarke, N. (2018). Primary Mutational Landscape Linked with Pre-docetaxel Lactate Dehydrogenase Levels Predicts Docetaxel Response in Metastatic Castrate-resistant Prostate Cancer. European Urology Focus. https://doi.org/10.1016/j.euf.2018.04.006

Published in:

European Urology Focus

\section{Citing this paper}

Please note that where the full-text provided on Manchester Research Explorer is the Author Accepted Manuscript or Proof version this may differ from the final Published version. If citing, it is advised that you check and use the publisher's definitive version.

\section{General rights}

Copyright and moral rights for the publications made accessible in the Research Explorer are retained by the authors and/or other copyright owners and it is a condition of accessing publications that users recognise and abide by the legal requirements associated with these rights.

\section{Takedown policy}

If you believe that this document breaches copyright please refer to the University of Manchester's Takedown Procedures [http://man.ac.uk/04Y6Bo] or contact uml.scholarlycommunications@manchester.ac.uk providing relevant details, so we can investigate your claim.

\section{OPEN ACCESS}


Urology Focus

Elsevier Editorial System(tm) for European

Manuscript Draft

Manuscript Number:

Title: Primary mutational landscape linked with pre-docetaxel LDH levels predicts docetaxel response in mCRPC

Article Type: Original Article

Section/Category: Prostate Cancer (PRO)

Keywords: Castrate Resistant Prostate Cancer; Lactate dehydrogenase; LDH; Taxane; Docetaxel; DNA Repair

Corresponding Author: Dr. Michael Brown, BSc. PhD.

Corresponding Author's Institution: University of Manchester

First Author: Kenneth Hiew

Order of Authors: Kenneth Hiew; Claire A Hart; Adnan Ali; Tony Elliott; Vijay Ramani; Vijay Sangar; Maurice Lau; Satish Maddineni; Michael Brown, BSc. PhD.; Noel W Clarke 
1 Primary mutational landscape linked with pre-docetaxel LDH levels predicts

4 Kenneth Hiew ${ }^{\mathrm{a}, \mathrm{b}}$, Claire A. Hart ${ }^{\mathrm{a}}$, Adnan Ali ${ }^{\mathrm{a}}$, Tony Elliott ${ }^{\mathrm{d}}$, Vijay Ramani ${ }^{\mathrm{c}, \mathrm{e}}$, Vijay

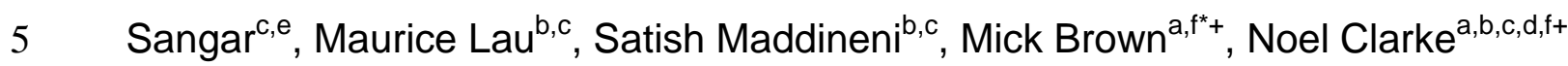

6

$7 \quad$ a. Genito Urinary Cancer Research Group, Division of Cancer Sciences, School of

8 Medical Sciences, Faculty of Biology, Medicine \& Health, The University of

9 Manchester, Manchester, M20 4QL, UK

10 b. Department of Urology, Salford Royal NHS Foundation Trust, Stott Lane,

11 Manchester M6 8HD, UK

12 c.Department of Urology, The Christie NHS Foundation Trust, Wilmslow Road,

13 Manchester, M20 4BX, UK

14 d.Department of Clinical Oncology, The Christie NHS Foundation Trust, Wilmslow

15 Road, Manchester, M20 4BX, UK

16 e.Department of Urology, University Hospital of South Manchester NHS Trust,

17 Manchester M23 9LT, UK

18 f.FASTMAN, Prostate Cancer UK, Movember Centre of Excellence

20 + Joint Senior Authors

$22{ }^{*}$ Correspondence Address:

23 Dr Mick Brown PhD

24 Genito Urinary Cancer Research Group,

25 MCRC Building 
26 Division of Cancer Sciences,

27 Faculty of Biology, Medicine \& Health,

28 The University of Manchester,

29 Wilmslow Road

30 Manchester,

31 M20 4BX,

32 UK

33 Tel: +447917137603

34

35

36 Keywords: Castrate Resistant Prostate Cancer; Lactate dehydrogenase; LDH;

37 Taxane; Docetaxel; DNA Repair

38

39 Abstract Word Count: 294

40 Main Text Word count: 2483 
41 Abstract:

42 Background

43 Docetaxel chemotherapy is a standard of care for metastatic castrate resistant

44 prostate cancer (mCRPC): $40-50 \%$ of patients achieve a biochemical response.

45 However, there is a lack of response predictive biomarkers.

46 Objective

47 Assess LDH as a docetaxel response biomarker in mCRPC. Examine LDH association with genomic alterations in primary diagnostic biopsies.

Design, Setting and Participants

50 Clinical and associated primary tumour targeted next-generation sequencing data

51 from matched training $(n=150)$ and test $(n=120)$ cohorts of progressive mCRPC patients receiving docetaxel therapy were analysed. Data was correlated with large scale prostate cancer genomic datasets.

Outcome measurements and Statistical Analysis

Prostate-specific antigen (PSA) response, radiographic response, biochemical progression-free (PFS), overall (OS) survival, genomic analysis of primary biopsies and genomic datasets (MSKCC, SUCF/PCF).

\section{Results and Limitations}

Serum $L D H \geq 450 U / L$ is a reliable prognostic biomarker [AUC:0.757 (SD 0.054 95\%

$60 \mathrm{Cl} 0.650-0.864 ; \mathrm{p}<0.001)]$ in progressive $\mathrm{mCRPC}$, predicting PFS at 3 months.

61 Patients with $\mathrm{LDH} \geq 450 \mathrm{U} / \mathrm{L}$ were poorer PSA responders, with shorter PFS (213 vs

62372 days, HR 1.876, 95\% Cl 1.289-2.7300) and OS (362 vs 563 days, HR 1.630,

$6395 \% \mathrm{Cl}$ 1.127-2.357. High LDH is an independent surrogate marker for survival

64 following docetaxel and predicts poor radiologic response $(p=0.043)$. Of the 14

65 patients with $L D H \geq 450 U / L$ available for NGS 9/14 (64.3\%) were more likely to have 
66 DNA repair gene mutation(s) (BRCA1/2, ATM, CHEK2, Fanconi's anaemia gene) in

67 their primary biopsy. Cross-correlation with MSKCC and SUCF/PCF databases

68 revealed a positive correlation between LDHA, PARP1 $(r=0.667 ; p<0.01)$ and other

69 DNA repair genes.

70 Conclusions

71 Genomic abnormalities of LDHA and DNA repair in primary biopsies link to high pre-

72 treatment LDH and poor response to docetaxel in mCRPC.

73 Patient Summary

74 The presence of mutations of the LDH and DNA repair pathways are associated with 75 aggressive prostate cancer and poor response to chemotherapy later in the disease. 


\section{Introduction:}

Docetaxel chemotherapy improves survival in men with $\mathrm{mCRPC}[1,2]$. It remains a valuable treatment for such patients. However, docetaxel resistance occurs in approximately $50 \%$, who have no biochemical or clinical response to therapy[2].

Some patients also respond to treatment initially but develop early therapeutic resistance. This creates uncertainty when deciding on the sequencing of treatments at this stage of the disease. There is therefore a need to explore biomarkers in relation to treatment outcomes that may help guide patient management. Lactate dehydrogenase (LDH) plays an important role in normal cellular glycolytic and gluconeogenesis pathways, it is dysregulated in cancer metabolism. Serum LDH level has clinical implications as a surrogate for overall survival and treatment response in several cancers[3-6].Understanding the molecular mechanisms that govern the development of high serum LDH levels prior to docetaxel chemotherapy may provide critical insight to cancer biology and treatment.

Genomic profiling is also used increasingly to guide cancer treatment e.g. colorectal cancer (30-50\% tumours with KRAS mutation), lung cancer (50\% tumours with EGFR mutation), and melanoma (25\% tumours with BRAF mutation [7-9]. In prostate cancer $(\mathrm{PCa})$ this has been problematic due to tumour heterogeneity but more recently, DNA repair linked genes have proved to be important in identifying response to DNA repair modulating drugs [10].

Herein we demonstrate the prognostic potential of serum LDH levels in MCRPC and develop this finding to link, for the first-time, LDH predicted response to docetaxel in 
102 mCRPC with genomic LDHA and DNA repair linked gene alterations present in the 103 primary biopsy at first diagnosis.

104 
105 Methods:

106 Cohort

107 A classical cohort $(\mathrm{N}=270)$ of docetaxel treated, progressing mCRPC (2005-2012)

108 were studied (REC\#07/H1003/161+5 10_NOCL_02). Archival FFPE primary

109 diagnostic prostate biopsy tissues were split into training $(n=150)$ and test $(n=120)$

110 cohorts. High Gleason grade tumour regions were defined by a uro-pathologist from

111 fresh H\&E sections. Blocks with incomplete clinical data, poor tissue quality, lack of

112 PCa related mortality were excluded on secondary screening. Clinic-pathological

113 data included age, Gleason score, M stage at initiation of docetaxel, alkaline

114 phosphatase, lactate dehydrogenase, albumin, PSA, and \%PSA fall after 6 cycles of

115 docetaxel. PSA progression was defined as per PCWG3 criteria. Radiographic

116 progression was defined as a $>20 \%$ increase in the sum of the diameters of soft-

117 tissue target lesions on $\mathrm{CT} / \mathrm{MRI}$ or $>2$ new lesions on bone scanning.

119 Statistics

120 Clinic-pathological characteristics at the time of initiation of docetaxel therapy were

121 recorded and cut-off points for LDH, ALP, and best PSA response were determined

122 by receiver operating characteristics (ROC) analysis, based on 3 month progression

123 free survival. The clinic-pathological associations were assessed by student t-test,

124 Wilcoxon rank sum and Chi-square tests. Cox regression analysis was used to

125 assess biomarker variables in univariate and multivariate analysis. Chi square test

126 assessed the predictive value of LDH in best PSA and radiologic response. Time to

127 event outcomes was evaluated by Kaplan-Meier. All statistical analyses were 2-sided

128 and performed at 95\% significance level using SPSS 20.1 software. 


\section{Genomic Analysis}

131 Regions of tumour were macro-dissected and DNA extracted using a proteinase K

132 buffer for 12-24h followed by Promega Maxwell 16 Tissue LEV DNA kit purification

133 as previously described[11]. Extracted DNA was quantified by standardised

134 PicoGreen fluorescence assay. Sequencing libraries were constructed from 200ng of

135 sheared DNA/total DNA (if <200ng was recovered). To correlate the NGS results,

136 the distribution of genetic alterations were dichotomised by pre-treatment LDH

137 levels. Total mutational burden/megabase of the 118 genes assessed was

138 determined[12] (Supplementary Methods). To calculate copy number alterations

139 (CNA) burden, the copy number of gains/losses was summed and calculated as a

140 percentage of the size of the coding region territory (Supplementary Methods).

141

142 Genomic Meta-Analysis

143 CBioPortal for Cancer Genomics (http://cioportal.org)[13] was used to explore

144 genetic alterations between LDHA and DNA repair genes in MSKCC[14], TCGA[15]

145 and SUCF/PCF[16] cohorts. Volcano plots were constructed with Plotly

146 (https://plot.ly). Findings were compared with the findings from primary tissue

147 genomic analysis.

148

149 
150 Results:

\section{Clinical Characteristics}

152270 patients receiving docetaxel with prednisolone at standard dose in 3-weekly

153 cycles between August 2005 and February 2012 were evaluated. Baseline

154 characteristics of patients responding to docetaxel were correlated with LDH and

155 ALP thresholds. Poor responders had significantly elevated LDH $(p=0.007)$ and ALP

$156(p=0.048)$ levels (Table 1). Higher and lower LDH cohorts had similar baseline

157 characteristic regarding age, treatment modalities, blood-based parameters, and

158 therapies following docetaxel treatment (Table 2).

160 Pre-docetaxel serum LDH correlates with progression free survival (PFS)

161 The median value for pre-treatment LDH was 517U/L (upper limit normal =550U/L).

162 In Figure 1, we compared LDH with ALP and best PSA response (\%fall of PSA post

1636 cycles of docetaxel)[17] as predictors of 3 month PFS in the combined cohort. Pre-

164 treatment serum LDH was the strongest biomarker for this (ROC 0.757 SD 0.054;

$16595 \% \mathrm{Cl} 0.650-0.864, \mathrm{p}<0.001)$. Reducing the cut-off to $450 \mathrm{U} / \mathrm{L}$ increased sensitivity

166 and specificity to $86.4 \%$ and $63.3 \%$ respectively compared with $81.8 \%$ and $50.2 \%$ at

$167517 \mathrm{U} / \mathrm{L}$ (Table 3). Focusing on the endpoint of 3 months PFS, LDH was the most

168 accurate tool for predicting PSA response in both training and test sets

169 (Supplementary Figure 1).

170

171 High mCRPC LDH correlates with adverse clinic-pathological characteristics

172 and docetaxel response. Pre-docetaxel clinic-pathological characteristics showed

173 that patients with $\mathrm{LDH} \geq 450 \mathrm{U} / \mathrm{L}$ had a higher PSA (median 383ng/L; range 2.3-

$1745325 n g / L$ vs 166ng/L; range 6.5-4453ng/L) and ALP (median 322U/L; 60-3112U/L vs 
$175139 \mathrm{U} / \mathrm{L}$; range 37-1736U/L) at initiationcompared to those with LDH $\leq 449 \mathrm{U} / \mathrm{L}$ (Table

176 4). Pre-treatment LDH $\geq 450 U / L$ patients had poorer PFS (median 255 vs 373 days,

$177 \mathrm{p}<0.001$ and 213 vs 372 days, $\mathrm{p}<0.001$ for training and tests sets respectively), and

178 OS (median 356 vs 514 days, $p=0.016$ and 362 vs 563 days, $p=0.011$ ) (Figure 3 ).

179 The prognostic potential of pre-treatment LDH was also seen in multivariate analysis

180 with the reported clinic-pathological markers (Supplementary Table 2).

181

$182 \mathrm{LDH} \geq 450 \mathrm{U} / \mathrm{L}$ correlated with a poor docetaxel response based on both \%fall of PSA

183 post docetaxel and radiological progression. Pre-treatment serum LDH $\geq 450 U / L$

184 correlated with progressive disease, as defined by any PSA rise after 6 cycles of

185 docetaxel (43.6\% vs. 21.3\%; $p=0.0004)$. However, pre-treatment serum LDH does

186 not predict a positive response to docetaxel. No significant difference was seen

187 between the two LDH cohorts in stable disease (20.4\% vs. $44.9 \%$; $p=0.8482)$ or in

188 partial responders (35.9\% vs. 33.7\%; $p=0.7868)$ (Figure 2 \& Table 5).

189

190 Radiological response was assessed in 71 (26.3\%) patients who had RECIST 1.1

191 measurable disease at baseline. Radiologic disease progression was seen in 32

192 (45\%), of whom $23(72 \%)$ had pre-treatment LDH levels $\geq 450 U / L$ (Table 5). Chi

193 square testing showed that LDH was prognostic of poor radiologic response

$194(p=0.043)$ unlike \%PSA or ALP falls $(p=0.755,0.838$ respectively $)$. However pre-

195 treatment LDH did not correlate with stable disease (SD) or partial response (PR)

196 (47.4\% vs. $52.6 \%, p=0.499$ and $55 \%$ vs. $45 \%, p=0.129$ respectively).

197

$198 \mathrm{LDH} \geq \mathbf{4 5 0 U} / \mathrm{L}$ is associated with higher frequency of genomic alterations in 199 primary biopsies 
200 Using LDH thresholds as a marker for poor response to docetaxel we dichotomised

201 our cohort and performed targeted next generation sequencing (NGS) on primary

202 diagnostic biopsy tissue to characterise the genomic landscape at the point of

203 diagnosis to ascertain whether the molecular profile at diagnosis was associated with

204 LDH levels and response to docetaxel treatment in mCRPC (Figure 4). Analysis was

205 limited to previously described functional alterations and excluded variants of

206 unknown significance (VUS). 21 samples with available primary diagnostic tissue

207 (Supplementary Table 1) were analysed, of which 14 were linked with pre-treatment

$208 \mathrm{LDH} \geq 450 \mathrm{U} / \mathrm{L}$ and 7 had $\mathrm{LDH} \leq 450 \mathrm{U} / \mathrm{L}$. LDH $\geq 450 \mathrm{U} / \mathrm{L}$ samples had a higher tumour

209 mutational load (TMB) (mean 46.2 vs 6.2 mut/MB; $p=0.129$ Supplementary Figure

$2102 \mathrm{~A}$ ) and higher Copy Number Alteration (CNA) (mean, 1.7\% vs 0.7\%; $p=0.3747$,

211 Supplementary Figure 2B) at the point of primary biopsy.

212

213 Correlations between LDHA mRNA expression and DNA repair mRNA gene

214 transcription. Genomic analysis of primary biopsies from pre-treatment LDH

$215 \geq 450 \mathrm{U} / \mathrm{L}$ patients showed mutations throughout the genomic regions tested. Of note

216 we observed a differential cluster within the DNA repair pathway. Tumour

217 aberrations in DNA-repair genes were observed in $(9 / 14,64 \%) \mathrm{LDH} \geq 450 \mathrm{U} / \mathrm{L}$

218 patients including 2 with somatic homozygous deletion of BRCA1, 1 somatic

219 homozygous deletion of BRCA2, 3 with ATM aberrations (1 truncation of the ATM

220 gene, 2 missense mutations) and 2 patients with homozygous deletions of CHEK2.

221 Mutations within DNA repair genes, such as Fanconi anaemia, ATR, MRE11 were

222 observed more commonly in the $\mathrm{LDH} \geq 450 \mathrm{U} / \mathrm{L}$ cohort $(6 / 14,42.8 \%)$ along with

223 mutations in TP53 (10/14, 71\%), a gatekeeper for response to DNA damage. Finally, 
224 8/14 (57\%) LDH $\geq 450 \mathrm{U} / \mathrm{L}$ patients had tumour aberrations in PI3K pathway signalling 225 genes.

227 To strengthen this association between mutations in the DNA repair pathway in 228 primary biopsy with pre-docetaxel serum LDH $\geq 450 \mathrm{U} / \mathrm{L}$, we performed a meta229 analysis of the localised PCa MSKCC cohort. Tumour specific expression of the 230 LDHA gene, which gives rise to the main monomer of the LDH enzyme, has a 231 positive correlation with PARP1 gene expression $(r=0.667, p<0.001$, Figure 5$)$. The

232 DNA repair genes, ATR, MLH1, and ATM also correlated with LDHA $(r=0.632$, $233 r=0.463, r=0.464, p<0.001$, Figure 5). This association was further examined in the 234 metastatic mCRPC SUCF/PCF cohort. Volcano plot analysis showed that 235 transcription of several DNA repair genes, including BRCA1 and BRCA2 was 236 upregulated in LDHA overexpressed samples (Figure 6A \& 6B, Table 6). Lastly, 237 LDHA positively correlated with PARP1 $(r=0.27, p<0.001)$, BRCA1/2, $(r=0.319$, $238 r=0.26 ; p<0.001)$ and CHEK2 $(r=0.412, p<0.001)$ gene expression in the TCGA 239 database (Supplementary Figure 4). 


\section{Discussion:}

242 The link between cancer metabolism and DNA damage is established and the

243 Warburg effect remains a key component of the dysregulation of energy metabolism

244 in this condition[18]. LDH becomes dysregulated in cancer cells and energy is

245 produced via glycolysis, rather than oxidative phosphorylation, resulting in increased

246 lactate production. The reasons underlying this metabolic shift are incompletely

247 understood but there is a clear linkage to activation of oncogenes and loss of tumour

248 suppressor genes, with associated genetic instability and compromised DNA repair.

250 The results of this study suggest that a subgroup of highly aggressive late stage

251 mCRPC patients, whose response to docetaxel in late stage disease is limited can

252 be identified by stratification according to the absolute level of serum LDH in late

253 stage failure, and that the genotype of these patients is identifiable in the genomic

254 profile at primary diagnosis. The subset of mCRPC patients with unfavourable

$255 \mathrm{LDH} \geq 450 \mathrm{U} / \mathrm{L}$ had a higher primary tumour mutational burden (TMB), with greater

256 incidence of defects in DNA repair and LDH-linked genes within their primary

257 diagnostic biopsy and this correlated with a poorer response to subsequent

258 docetaxel therapy on progression in the castrate resistant state. The frequencies of

259 somatic mutations of TP53 gene were also seen more commonly in this subset. Our

260 findings suggest that analyses of primary diagnostic tumour biopsy samples using

261 next generation sequencing methods can increase our understanding not only of the

262 biological aggression of a tumour at presentation, but also to its association with

263 treatment response to castration resistant progression . 
265 Our sample size for NGS analysis was small, but the data generated therefrom was consolidated through meta-analysis of large-scale cohorts, whose data support our NGS findings. The independent MSKCC cohort found expression of tumour specific LDHA, a dominant subunit of the LDH family, was positively associated with expression of the PARP1 gene, and several other DNA repair genes (ATR, MLH1, and ATM) at the mRNA level. A volcano plot analysis of the SUCF/PCF cohort, containing metastatic mCRPC samples also confirmed that DNA repair genes were associated with samples with overexpression of LDHA. Together, these data emphasise a congruent link between LDH, associated with the Warburg switch, and DNA repair genes as seen in our targeted next generation sequencing data, which is identifiable when the patient first presents.

Other studies[19-21] have shown that LDH alone is a surrogate for survival in the management of individual patients with mCRPC. Our data support this, adding further information which may be of clinical utility in relation to the use of docetaxel. Patients with an LDH threshold beyond $450 \mathrm{U} / \mathrm{L}$ generally failed in their response to treatment and when LDH levels are in excess of this threshold consideration might be given alternative therapeutic approaches as response to docetaxel in this setting is generally poor. However, this finding, whilst supportive of other studies is not new. By contrast, our identification of a high frequency of DNA repair gene mutations in the primary biopsy and their association with LDHA genes linked to high LDH levels and response to docetaxel treatment in later stages of their disease is novel. Whilst it might be argued that the high LDH levels observed in our poorly responding patients was a manifestation of lead time and disease burden, it is hard to reconcile this with the fact that the DNA repair and LDH linked genetic aberrations were present at the 
290 initial diagnosis in the majority of these patients. This suggests that the association is

291 true and that the mechanistic link is worth exploring further. It may be of value to

292 screen men with high risk localised and de-novo metastatic PCa to test the

293 hypothesis that this group of patients might be sub-selected for a different treatment

294 pathway rather than involving conventional Taxane based approaches.

295

296 There are a number of limitations in this study, the relatively modest size and

297 classical pre-abiraterone/enzalutamide cohort nature. The higher overall incidence of

298 genomic defects in DNA repair genes in our cohort $(42.8 \%(9 / 21))$ compared to

299 previous reports[16,22,23] reflects the aggressive nature of the final disease of this

300 cohort. It is unclear whether this enrichment is secondary to a tumour evolution

301 process from localised disease to metastasis, or small sampling size. However, this

302 weakness arising from the relatively small numbers is mitigated by the consistency of

303 data when comparing large genomic data banks from patients with a spectrum of

304 clinically indolent and clinically aggressive disease whose natural history is

305 established. We believe this consistency in the data trend and the presence in pre-

306 treatment biopsies adds weight to the notion that our findings show a true effect. 


\section{Conclusions}

309 Serum LDH level at the point of initiation of docetaxel therapy in progressive mCRPC

310 is a strong prognostic marker for PFS and OS and levels $\geq 450$, indicative of poor

311 response, may be of use in therapy selection in these patients. Late failure with high

312 serum LDH is associated with a high frequency of genomic alterations in LDHA and

313 DNA linked repair genes in primary biopsies. This group of patients have an

314 aggressive phenotype and exhibited a poor response to docetaxel based

315 chemotherapy in the castrate resistant state. Our data adds evidence to the notion

316 that there is a primary metabolic, gene associated linkage to a high energy driven

317 glycolytic status within PCa cells which drives a biologically aggressive phenotype.

318 Further interrogation of this process may help to refine predictive signatures of

319 aggression in clinically localised disease, sub-select patients who may not respond

320 to docetaxel based chemotherapy and also, further our understanding of the inter-

321 relationship between dysfunctional energy handling in cancer cells and the resultant

322 progression through the metastatic process. 
325 Acknowledgements:

326 We would like to thank Hitesh Minstry for his statistical advice and the MCRC

327 Biobanking facility for sample retrieval support.

328 
329 References:

330 1. Petrylak, D.P., Tangen, C.M., Hussain, M.H., et al. Docetaxel and

331 estramustine compared with mitoxantrone and prednisone for advanced

332 refractory prostate cancer. N Engl J Med. 2004. 351: 1513-20.

333 2. Tannock, I.F., de Wit, R., Berry, W.R., et al. Docetaxel plus prednisone or

$334 \quad$ mitoxantrone plus prednisone for advanced prostate cancer. N Engl J Med.

335 2004. $351: 1502-12$.

336 3. Giroux Leprieur, E., Lavole, A., Ruppert, A.M., et al. Factors associated with

337 long-term survival of patients with advanced non-small cell lung cancer.

$338 \quad$ Respirology. 2012. 17: 134-42.

339 4. Jin, Y., Ye, X., Shao, L., et al. Serum lactic dehydrogenase strongly predicts

$340 \quad$ survival in metastatic nasopharyngeal carcinoma treated with palliative

341 chemotherapy. Eur J Cancer. 2013. 49: 1619-26.

342 5. Motzer, R.J., Escudier, B., Bukowski, R., et al. Prognostic factors for survival

343 in 1059 patients treated with sunitinib for metastatic renal cell carcinoma. $\mathrm{Br} \mathrm{J}$

$344 \quad$ Cancer. 2013. 108: 2470-7.

345 6. Wan, X.B., Wei, L., Li, H., et al. High pretreatment serum lactate

346 dehydrogenase level correlates with disease relapse and predicts an inferior

347 outcome in locally advanced nasopharyngeal carcinoma. Eur J Cancer. 2013.

$348 \quad 49: 2356-64$.

349 7. Long, G.V., Menzies, A.M., Nagrial, A.M., et al. Prognostic and

$350 \quad$ clinicopathologic associations of oncogenic BRAF in metastatic melanoma. J

$351 \quad$ Clin Oncol. 2011. 29: 1239-46.

352 8. Shim, H.S., Lee, D.H., Park, E.J., and Kim, S.H. Histopathologic

353 characteristics of lung adenocarcinomas with epidermal growth factor receptor 
mutations in the International Association for the Study of Lung Cancer/American Thoracic Society/European Respiratory Society lung adenocarcinoma classification. Arch Pathol Lab Med. 2011. 135: 1329-34.

9. Wilson, P.M., Labonte, M.J., and Lenz, H.J. Molecular markers in the treatment of metastatic colorectal cancer. Cancer J. 2010. 16: 262-72.

10. Mateo, J., Carreira, S., Sandhu, S., et al. DNA-Repair Defects and Olaparib in Metastatic Prostate Cancer. N Engl J Med. 2015. 373: 1697-708.

11. Beltran, H., Yelensky, R., Frampton, G.M., et al. Targeted next-generation sequencing of advanced prostate cancer identifies potential therapeutic targets and disease heterogeneity. Eur Urol. 2013. 63: 920-6.

12. Chalmers, Z.R., Connelly, C.F., Fabrizio, D., et al. Analysis of 100,000 human cancer genomes reveals the landscape of tumor mutational burden. Genome Med. 2017. 9: 34.

13. Cerami, E., Gao, J., Dogrusoz, U., et al. The cBio cancer genomics portal: an open platform for exploring multidimensional cancer genomics data. Cancer Discov. 2012. 2: 401-4.

14. Taylor, B.S., Schultz, N., Hieronymus, H., et al. Integrative genomic profiling of human prostate cancer. Cancer Cell. 2010. 18: 11-22.

15. Network, C.G.A.R. The Molecular Taxonomy of Primary Prostate Cancer. Cell. 2015. 163: 1011-25.

16. Robinson, D., Van Allen, E.M., Wu, Y.M., et al. Integrative clinical genomics of advanced prostate cancer. Cell. 2015. 161: 1215-1228.

17. Guinney, J., Wang, T., Laajala, T.D., et al. Prediction of overall survival for patients with metastatic castration-resistant prostate cancer: development of a 
prognostic model through a crowdsourced challenge with open clinical trial data. Lancet Oncol. 2017. 18: 132-142.

18. Warburg, O., Wind, F., and Negelein, E. The Metabolism of Tumors in the Body. J Gen Physiol. 1927. 8: 519-30.

19. Berry, W.R., Laszlo, J., Cox, E., Walker, A., and Paulson, D. Prognostic factors in metastatic and hormonally unresponsive carcinoma of the prostate. Cancer. 1979. 44: 763-75.

20. Halabi, S., Small, E.J., Kantoff, P.W., et al. Prognostic model for predicting survival in men with hormone-refractory metastatic prostate cancer. J Clin Oncol. 2003. 21: 1232-7.

21. Scher, H.I., Heller, G., Molina, A., et al. Circulating tumor cell biomarker panel as an individual-level surrogate for survival in metastatic castration-resistant prostate cancer. J Clin Oncol. 2015. 33: 1348-55.

22. Frampton, G.M., Fichtenholtz, A., Otto, G.A., et al. Development and validation of a clinical cancer genomic profiling test based on massively parallel DNA sequencing. Nat Biotechnol. 2013. 31: 1023-31.

23. Grasso, C.S., Wu, Y.M., Robinson, D.R., et al. The mutational landscape of lethal castration-resistant prostate cancer. Nature. 2012. 487: 239-43. 
400

401

402

403

404

405

406

407

408

409

410

411

412

413

414

415

416

417

418

419

420

421

422

423

424

\section{Table Legends}

Table 1: Baseline descriptive characteristics of chemoresponsive and chemoresistant patients in the training set $(n=150)$. The association of clinicpathological characteristics of cohorts were assessed by student t-test, Wilcoxon rank sum test and Chi-square test for continuous (Age, PSA at initiation of docetaxel, LDH, ALP, Hb, Albumin) and categorical (Presence of bone metastases, and presence of visceral metastases) variables respectively.

Table 2: Baseline descriptive characteristics of the training $(n=150)$ and test $(n=120)$ sets. The association of clinic-pathological characteristics of both cohorts were assessed by student t-test, Wilcoxon rank sum test and Chi-square test for continuous (age, LDH, ALP, Hb, albumin, PSA at initiation of docetaxel) and categorical [treatment modalities at M0/M1 stage, metastatic stage (M1a/b/c), post docetaxel treatment, and PSA responders] data respectively.

\section{Table 3: Progression Free Survival sensitivity and specificity using pre-} treatment serum LDH. The upper limit normal of LDH value used at the Christie is $550 \mathrm{U} / \mathrm{L}$. The median value of training, test and combined cohort is 546,493 and 517 respectively. The sensitivity and specificity of $\mathrm{LDH}>450 \mathrm{U} / \mathrm{L}$ as a prognostic biomarker is reported at the bottom row for each cohort. The sensitivity and specificity were calculated based on AUC analysis, using SPSS. 
425 statistics between LDH expression and selected clinic-pathological characteristics

426 among men treated with docetaxel chemotherapy at castrate level in combined

427 cohort. Unpaired student t test and Wilcoxon rank sum test was used for continuous

428 variables. Chi square test was used for categorical variables. Abbreviation: LN:

429 lymph node.

430

431 Table 5: Pre-treatment LDH $\geq 450 U / L$ correlates with poor docetaxel response.

432 Docetaxel response was based on \%fall in PSA, or by radiological progression in

433 patients who had RECIST (v1.1) measurable disease at baseline. Progressive

434 disease was defined as any rise in PSA after 6 cycles of treatment or a $>20 \%$

435 increase in the sum of the diameters of the lesion on CT/MRI or $>2$ new bone

436 lesions.

437

438 Table 6: LDHA expression correlates with DNA repair genes in the SU2C/PCF

439 cohort. Expression of DNA repair genes (RAD18, BRCA1, EZH2, PARP1, BRCA2,

440 CHEK2, ATM, MLH1, ATR) within the metastatic prostate samples $(n=118)$ from the

441 SU2C/PCF database were correlated with altered LDHA expression. Data presented

442 as mean mRNA expression+/- standard deviation (SD)

443

444 
446

447

448

449

450

451

452

453

454

455

456

457

458

459

460

461

462

463

464

465

466

467

468

469

\section{Figure Legends}

Figure 1: LDH is the most accurate prognostic indicator. ROC Curve analysis comparing LDH, ALP and Best PSA response as a predictor of 3 month PFS. Best PSA response is defined as \% fall of PSA post 6 cycle of docetaxel.

Figure 2: Pre-treatment serum LDH of $\geq 450 \mathrm{U} / \mathrm{L}$ predicts docetaxel treatment failure. Waterfall plots depicting best Prostate Specific Antigen (PSA) response dichotomised by $<450 U / L$ (red) or $\geq 450 U / L$ (blue) LDH levels. Best PSA response was measured based on percentage changes from PSA level at 1st cycle of docetaxel chemotherapy to the end of 6th cycle of docetaxel chemotherapy.

Figure 3: Serum LDH is prognostic for progression free and overall survival in mCRPC patients. Kaplan Meier Progression free survival (PFS) analysis dichotomised by pre-treatment serum LDH levels $<450$ or $\geq 450 \mathrm{U} / \mathrm{L}$ for training $(A)$ and test (B) sets. Kaplan Meier Overall Survival (OS) analysis dichotomised by pretreatment serum LDH levels $<450$ or $\geq 450 \mathrm{U} / \mathrm{L}$ for training $(C)$ and Test $(D)$ sets.

Figure 4: The genomic landscape of primary prostate cancer patients. The genomic landscape of primary diagnostic biopsies from patients $(n=21)$ who later went on to be treated with docetaxel for mCRPC, dichotomised by pre-treatment LDH levels (<450 vs. $\geq 450 U / L$ ), was determined on the FoundationOne platform. Genes were grouped according to function: 1 . Tumour suppressor genes; 2 . AR; 3 . Metabolism; 4. DNA repair; 5. PIK3CA/AKT pathway; 6. Transcription; 7:

Chemotaxis; 8. Apoptosis; 9. Oncogene; 10. Wnt signalling; 10. TGF signalling. 
471 Figure 5: Meta-analysis of the MSKCC cohort shows a link between LDHA and

472 DNA repair genes. Scatterplot analysis of normalised LDHA mRNA expression vs

473 A) PARP1, B MLH1, C)ATM, D) ATR mRNA expression. Expression shown as log2

474 whole transcript mRNA expression (Affymetrix Human Exon 1.0 ST arrays). Pearson

475 correlation statistical analysis was used to compare the linear association of specific 476 genes.

477

478 Figure 6: Meta-analysis of the metastatic CRPC SUCF/PCF cohort shows a link 479 between LDHA and DNA repair genes. Volcano plot of SUCF/PCF cohort showing 480 the differential expressed genes, dichotomised by the LDHA gene. The spots above 481 the horizontal line represent genes with statistically significant expression differences 482 with respect to controls. A total of 14660 genes were analysed. A mean value was 483 deduced following the deduction of mean mRNA expression of the altered group and 484 non-altered group. Positive mean changes indicate up-regulation compared with the 485 unaltered group, while negative mean changes indicate down-regulation. High 486 log10pvalue indicates an increased statistical significance in the studied gene 487 expression in relation to the LDHA altered/unaltered groups. 
Pre-treatment serum LDH levels are prognostic for docetaxel therapy failure within the metastatic castrate resistant prostate cancer setting, and is linked to a genomic subtype present in a high proportion of these patients at the point of diagnostic biopsy. 


\section{Patient characteristics}

Age (mean \pm SD)

PSA at initiation of docetaxel

LDH

median (range)

ALP

median (range)

$\mathrm{Hb}$

median (range)

Albumin

median (range)

$M$ stage

Bone metastases, n (\%)

YES

NO

Visceral metastases, $\mathrm{n}(\%)$

YES

NO
Chemosensitive Chemoresistant p value $(n=93)$

$66 \pm 8$

576.9

$(\mathrm{n}=57)$

$67 \pm 7 \quad 0.127$

$462.1 \quad 0.610$

$522(245-3000) \quad 625(359-3710) \quad 0.007$

$232(49-1451) \quad 304(70-3112) \quad 0.048$

$11.8(8.5-15.6) \quad 11.5(8.6-14.3) \quad 0.239$

$43(32-49) \quad 42(34-51) \quad 0.112$

$68(73.1 \%)$

$47(82.5 \%)$

$10(17.5 \%)$

0.208

$25(26.9 \%)$

$13(22.8 \%)$

$44(77.2 \%)$
$7(7.5 \%)$

$86(92.5 \%)$
0.028 


\section{Patient Characteristics}

Number of patients

Age, median (range), y

$\mathrm{M} 0$ at diagnosis

M1 at diagnosis training set

150

67 (49-81)

$\mathrm{n}=92$

$\mathrm{n}=58$
Primary treatment, No. (\%)

Prostatectomy

Radiotherapy

Brachytherapy

Primary ADT

ADT for M1 Disease
5 (5.4)

48 (52.1)

4 (6.5)

35 (38.0)

58 (100.0)
45 (100.0) test set

120

p value

$68(54-80)$

0.056

$\mathrm{n}=75$

$\mathrm{N}=45$

Metastatic disease status at initiation of docetaxel chemotherapy, No. (\%)

LN only (M1a)

Bone +/- LN (M1b)

Visceral +/- Bone+/- LN (M1c)

Laboratory measures, median (range)

$\mathrm{LDH} \mathrm{U/L}$

Haemoglobin g/DL

ALP U/L

Albumin, g/DL

PSA, ng/mL

\section{Postdocetaxel treatment (\%)}

AR therapies-

arbiraterone/enzalutamide only

Taxanes- rechallenge docetaxel, cabazitaxel

AR and Taxanes

Palliative care

Others, radium 223, clinical trials etc.

PSA response (\%)

Partial response

Stable disease

Progressive disease
$34(22.7)$

$30(25.0)$

0.676

$96(64.0)$

85 (70.8)

0.266

20(13.3)

5 (4.2)

0.009
0.498

0.143

0.318

0.008

8



Sensitivity and Specificity for predicting 3 months PFS, by cutoffs of LDH

\begin{tabular}{|c|c|c|c|c|c|c|c|}
\hline & & Training & $t(n=150)$ & Test se & $(n=120)$ & $\underset{(n=}{\text { Combin }}$ & $\begin{array}{l}\text { d cohort } \\
\text { 70) }\end{array}$ \\
\hline & U/L & Sensitivity & Specificity & Sensitivity & Specificity & Sensitivity & Specificit \\
\hline & $\begin{array}{l}\text { limit } \\
\text { al) }\end{array}$ & 81.8 & $45.3 \%$ & $63.6 \%$ & $29.7 \%$ & 72.7 & 40.4 \\
\hline & 546 & $81.8 \%$ & $47.4 \%$ & 63.6 & 31.2 & 72.7 & 42.4 \\
\hline 잉 & 517 & 90.9 & 53.3 & 72.7 & 39.9 & 81.8 & 50.2 \\
\hline & 493 & $90.9 \%$ & 59.9 & 72.7 & $44.9 \%$ & 86.4 & 55.1 \\
\hline & & $95.2 \%$ & $68.6 \%$ & $81.1 \%$ & $50.7 \%$ & 86.4 & 63.3 \\
\hline
\end{tabular}


Characteristics

Patients, n (\%)

Age at initiation of docetaxel, median (range)

PSA at initiation of treatment, median (range)

Bone only

LN only

LN + Bone only

LN + Bone + visceral only

Haemoglobin

ALP

Albumin
Overall cohorts $(\mathrm{n}=\mathbf{2 7 0}$ )

p value

$\begin{array}{ccc}\text { High }(\geq 450) & \text { Low }(<449) & \\ 181 & 89 & \\ 68(52-83) & 68(49-83) & 0.183 \\ 383(2.3-5325) & 166(6.5-4453) & <0.001 \\ 94(51.9) & 41(46.1) & \\ 18(9.9) & 9(10.1) & \\ 40(22.1) & 30(33.7) & 0.158 \\ 29(16.1) & 9(10.1) & \\ 11.3(7.5-16.3) & 12.1(8.3-15.6) & <0.001 \\ 321.5(60-3112) & 139(37-1736) & <0.001 \\ 42(34-51) & 43(32-49) & 0.253\end{array}$


$<449$ LDH $\quad \geq 450$ LDH $\quad$ p value

PSA responder, $\mathbf{n}(\%)$

Partial responder (>50\% fall in PSA) $\quad 30(33.7) \quad 65(35.9) \quad 0.7868$

Stable disease (<49\% fall PSA) $\quad 40(44.9) \quad 37(20.4) \quad 0.8482$

$\begin{array}{llll}\text { Progressive disease (any PSA rise) } & 19(21.3) & 79(43.6) & \mathbf{0 . 0 0 0 4}\end{array}$

Best radiologic response, $\mathrm{n}(\%)$

Partial responder

$11(55.0) \quad 9(45.0) \quad 0.129$

Stable disease

$9(47.4) \quad 10(52.6) \quad 0.499$

Progressive disease

$9(28.1) \quad 23(71.9) \quad 0.048$ 


\begin{tabular}{|c|c|c|c|c|c|}
\hline \multirow[t]{2}{*}{ Gene } & \multirow[t]{2}{*}{ Cytoband } & \multicolumn{2}{|c|}{$\begin{array}{c}\text { Mean mRNA expression } \\
\pm \text { SD }\end{array}$} & \multirow[t]{2}{*}{$p$ value } & \multirow[t]{2}{*}{$q$ value } \\
\hline & & $\begin{array}{l}\text { Altered } \\
\text { group }\end{array}$ & $\begin{array}{l}\text { Un-altered } \\
\text { group }\end{array}$ & & \\
\hline RAD18 & $3 p 25.3$ & $2.75 \pm 0.40$ & $1.94 \pm 0.95$ & $2.64 \times 10^{-6}$ & $2.852 \times 10^{-3}$ \\
\hline BRCA1 & $17 q 21$ & $3.06 \pm 1.06$ & $1.53 \pm 0.99$ & $1.831 \times 10^{-4}$ & 0.0153 \\
\hline EZH2 & $7 q 35-q 36$ & $4.19 \pm 0.97$ & $2.74 \pm 0.94$ & $1.307 \times 10^{-4}$ & 0.0139 \\
\hline PARP1 & $1 q 41-q 42$ & $6.20 \pm 0.85$ & $5.44 \pm 0.79$ & $8.096 \times 10^{-3}$ & 0.0807 \\
\hline BRCA2 & $13 q 12.3$ & $0.81 \pm 1.87$ & $-0.74 \pm 1.39$ & 0.0121 & 0.0982 \\
\hline CHEK2 & $22 q 12.1$ & $2.67 \pm 0.96$ & $2.05 \pm 0.78$ & 0.0415 & 0.185 \\
\hline ATM & $11 q 22-q 23$ & $2.84 \pm 0.74$ & $2.45 \pm 0.82$ & 0.0982 & 0.293 \\
\hline MLH1 & $3 p 21.3$ & $4.02 \pm 0.68$ & $3.82 \pm 0.61$ & 0.336 & 0.572 \\
\hline ATR & $3 q 23$ & $3.50 \pm 0.76$ & $3.57 \pm 0.73$ & 0.766 & 0.878 \\
\hline
\end{tabular}


Click here to download high resolution image

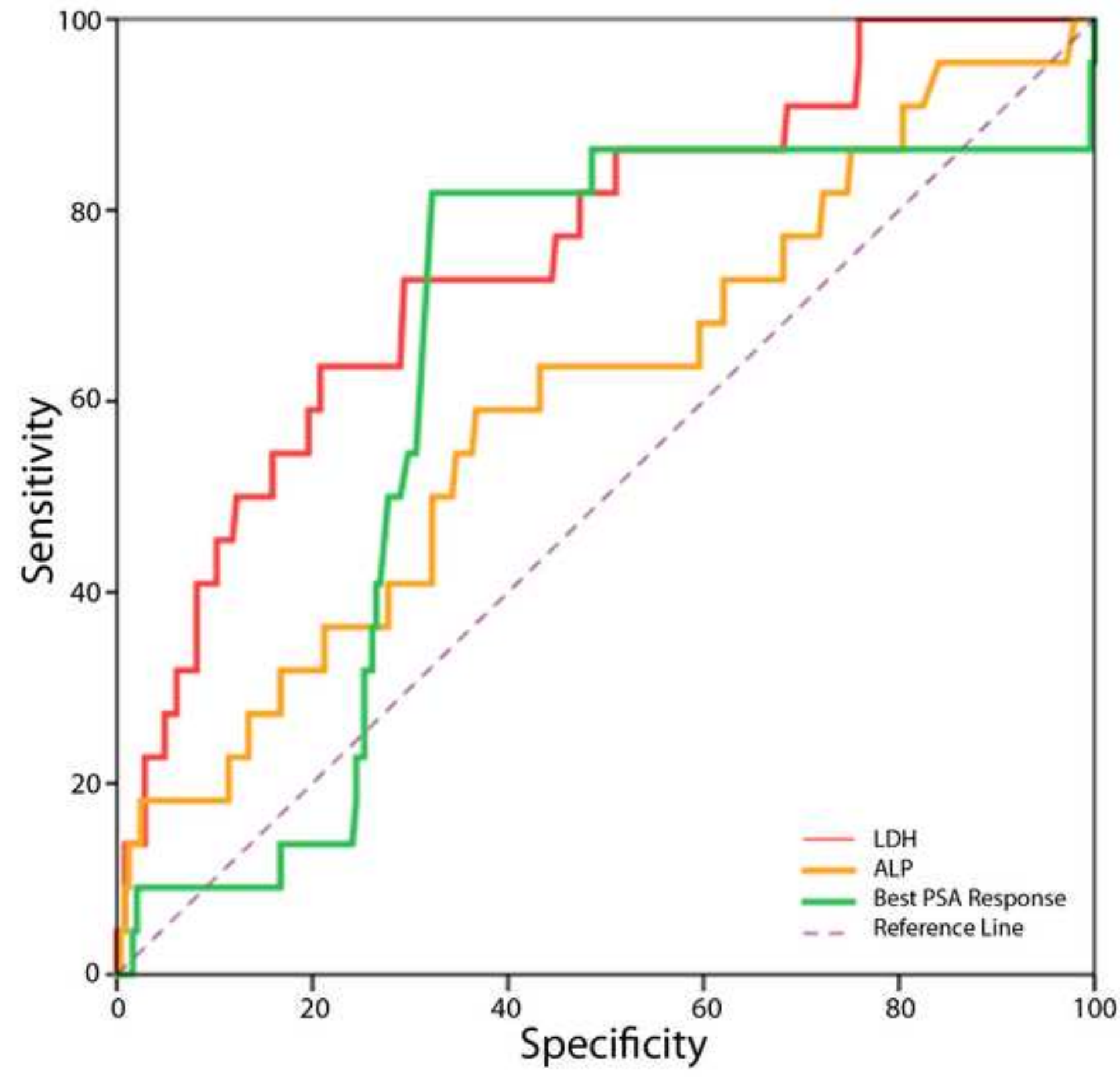


Figure 2
Click here to download high resolution image
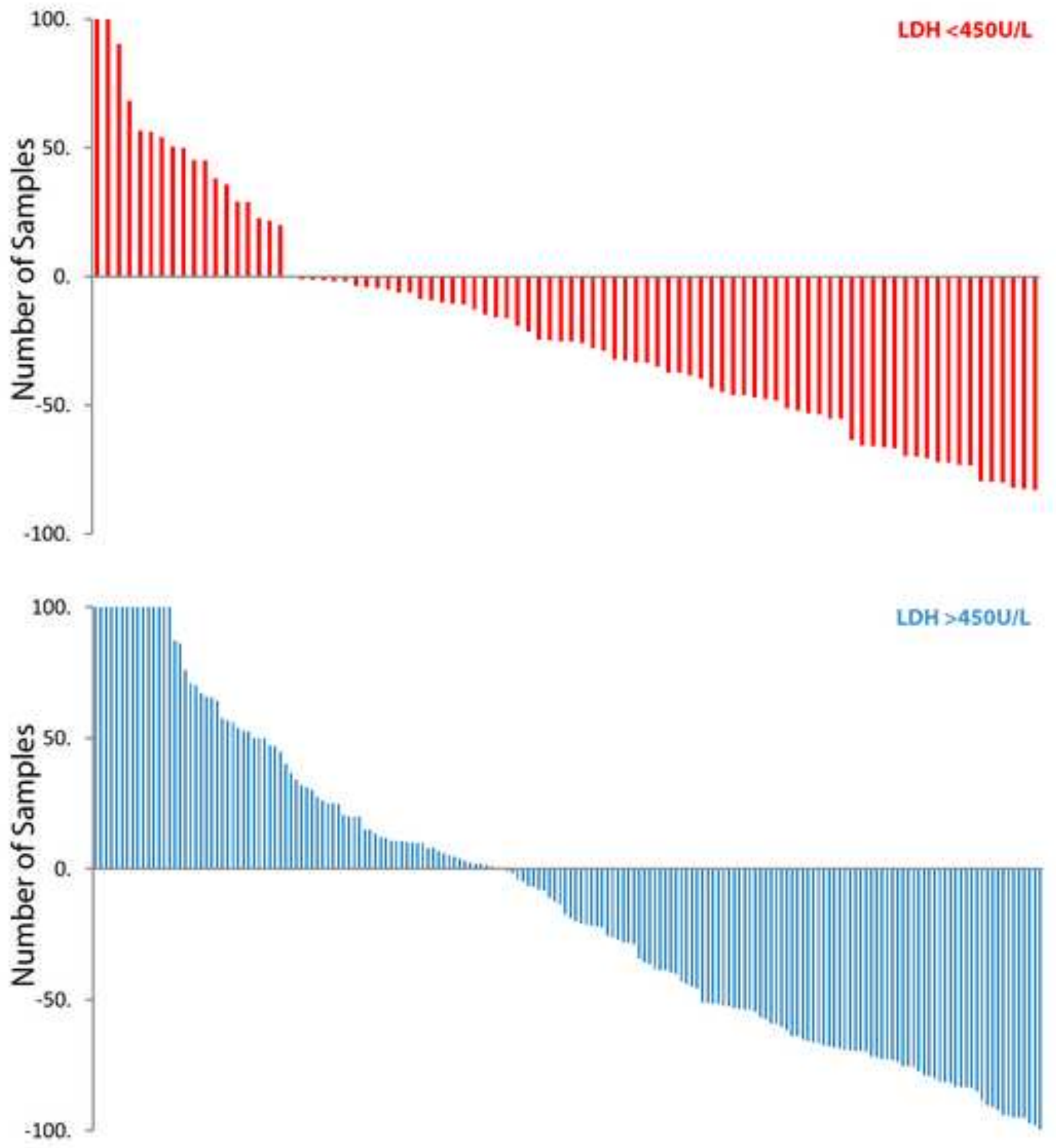

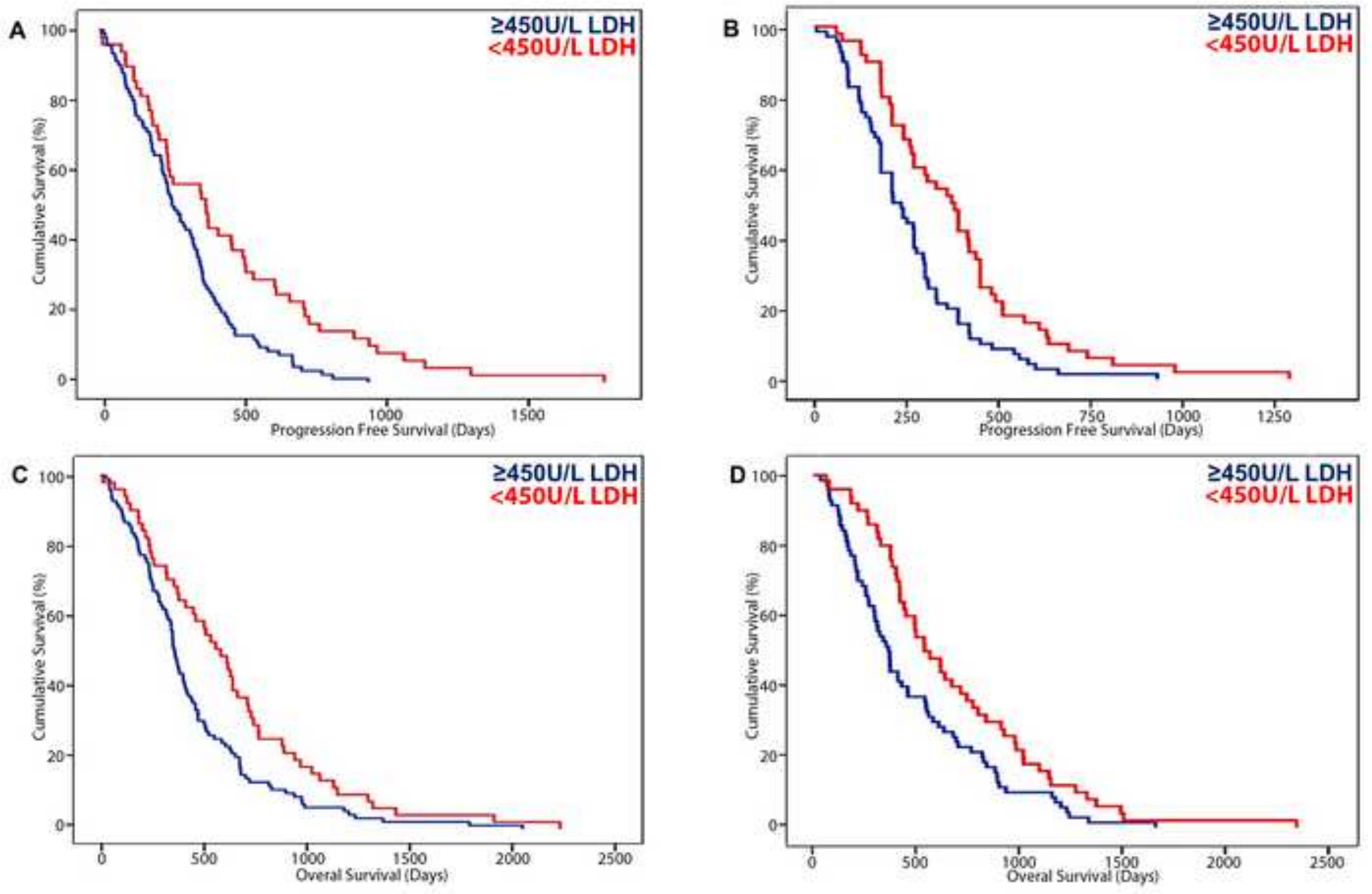
Figure 4

Click here to download high resolution image

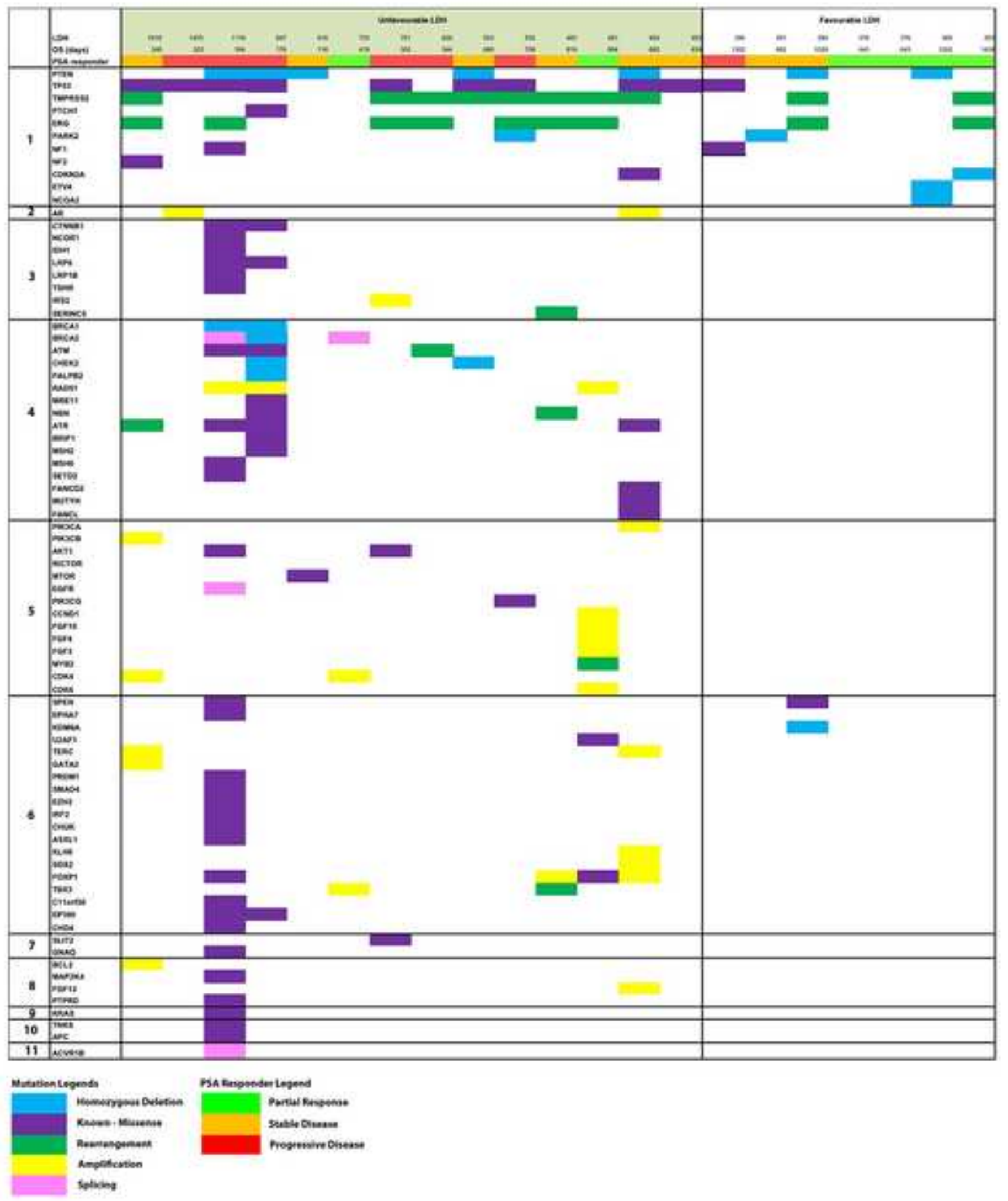



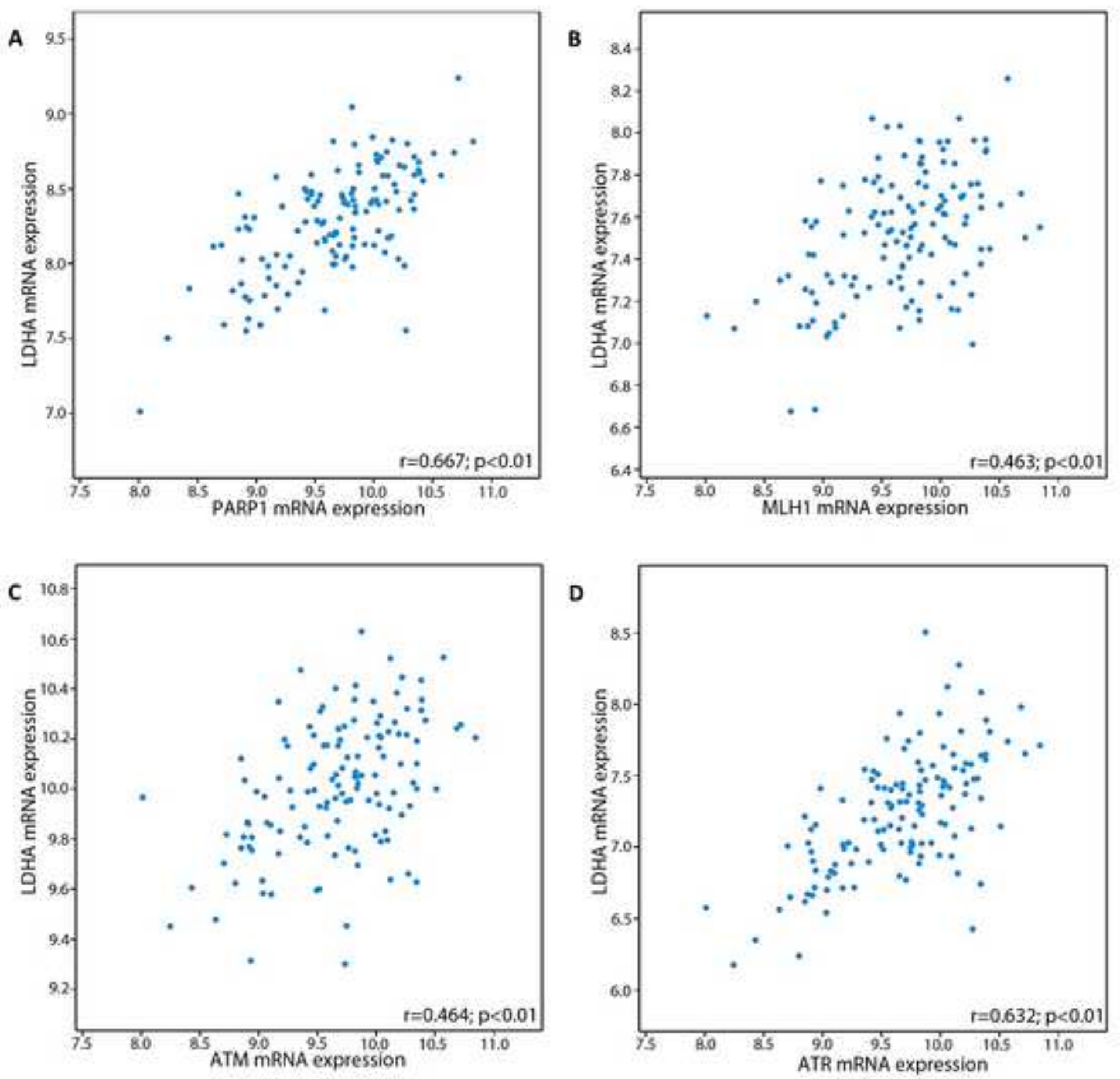
Click here to download high resolution image

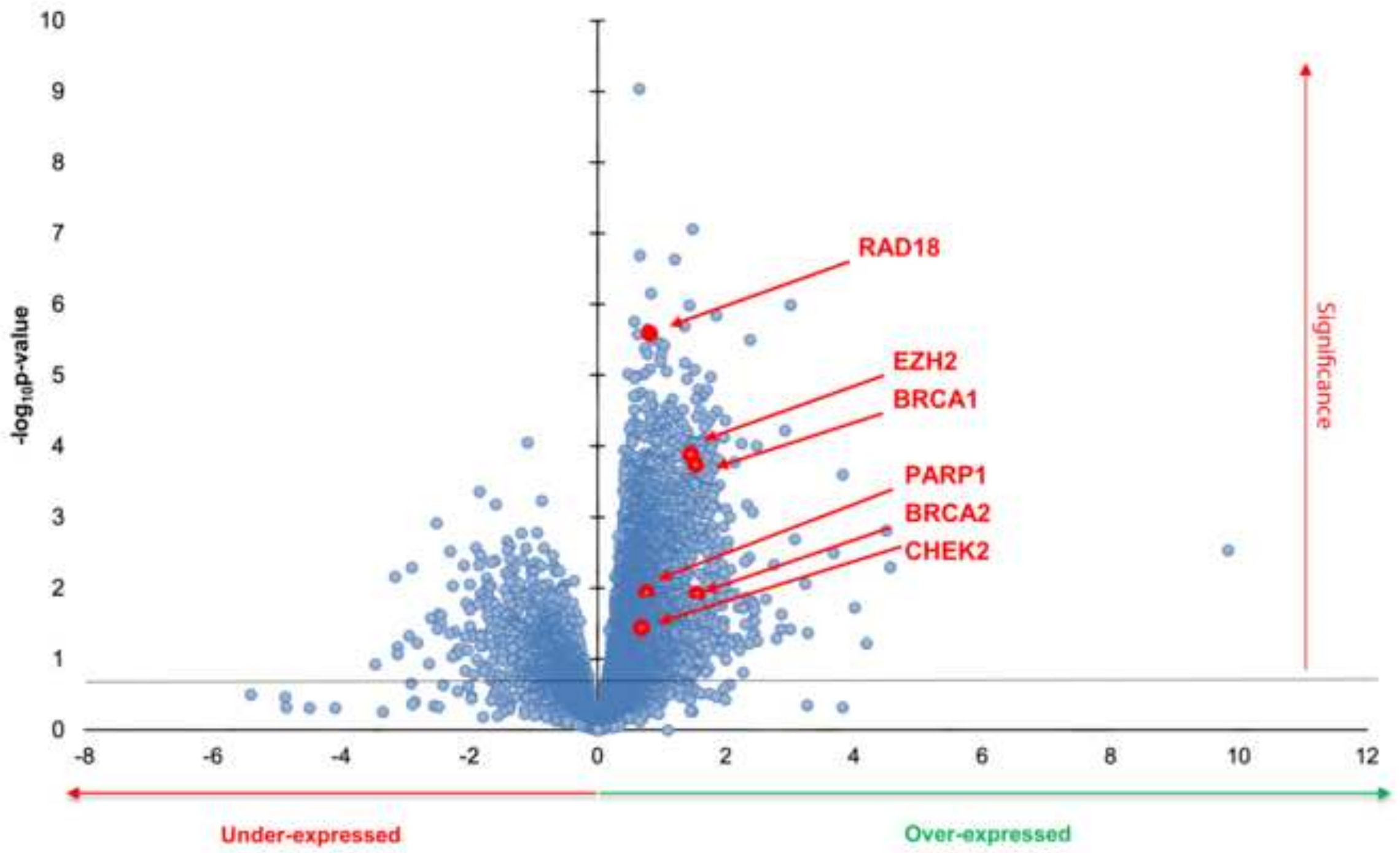




\section{Supplementary Methods}

\section{Patient samples}

270 mCRPC patients who underwent docetaxel therapy for progressive disease between 2005 and 2012. The cohort was dichotomised in to a training $(n=150)$ and test $(n=120)$ set. The study was conducted with full ethical approval. Archived formalin fixed paraffin embedded (FFPE) diagnostic transrectal ultrasound (TRUS)-guided prostate or Transurethral resection of prostate (TURP) tissue was retrieved for each case and clinically significant regions of tumour defined by an uro-pathologist from H\&E sections. Blocks with incomplete clinical data, poor tissue quality, and lack of $\mathrm{PCa}$ related mortality were excluded on secondary screening. Clinic-pathological data included age, Gleason score, M stage $(\mathrm{M} 1 \mathrm{a} / \mathrm{b} / \mathrm{c})$ at initiation of docetaxel chemotherapy, alkaline phosphatase, lactate dehydrogenase, albumin, PSA, and \% PSA fall post 6 cycles of docetaxel.

\section{DNA extraction, library preparation and sequencing.}

Targeted next-generation sequencing studies (NGS) were conducted by Foundation Medicine as previously described [1]. Regions of tumour were macro-dissected and DNA extracted using a proteinase $\mathrm{K}$ buffer for $12-24 \mathrm{~h}$ followed by purification with the Promega Maxwell 16 Tissue LEV DNA kit as previously described [1]. Extracted DNA was quantified by standardised PicoGreen fluorescence assay. 200ng of sheared DNA was recovered from samples or total DNA from samples with less than $200 \mathrm{ng}$ was used to construct from sequencing libraries. Libraries were constructed with the use with custom biotinylated RNA oligo pools (custom SureSelect kit, Agilent) representing 3167 exons of 118 cancer-related genes plus 18 introns of 6 genes often rearranged in cancer (Supplementary Table 3). Pair end sequencing (49 x49 cycles) was performed using the HiSeq 2000 (Illumina). Sequence data from genomic DNA and cDNA were mapped to the human genome as previously described [1,2].

\section{Microarray data analysis:}

We explored 3 microarray data sets to analyse the association of genes with LDHA, the main monomer of $\mathrm{LDH}$.

1. MSKCC Prostate Cancer Oncogenome Group dataset consists of 218 prostate tumours (181 primaries, 37 metastases) and 12 prostate cancer cell lines and xenografts, using Agilent Human Exon 1.0 ST array [3]. The expression array data were downloaded from MSKCC cbioportal under accession number GSE21032 (cbio.mskcc.org/cancergenomics/prostate/data/). Primary tumours with complete mRNA data $(n=131)$ were included; all metastatic samples were excluded. To examine the association of genes involved in DNA repair pathway and LDHA in MSKCC cohort, log2 whole transcript mRNA expression values of each gene from downloaded process data (Affymetrix Human Exon 1.0 ST array) were used as scatterplots. Pearson correlation coefficient was used to measure the linear correlation between LDHA and individual genes in DNA repair pathway.

2. The Cancer Genomics Atlas (TCGA) consortium dataset consists of 383 samples: 50 benign samples and 333 primary tumours, using IlluminaGA RNA Seq [4]. The expression array data were downloaded from UCSC Cancer Genome Browser (https://genomecancer.ucsc.edu/) - TCGA_PRAD_exp_HiSeqV2-2014-05-02.tgz. Associated clinical data were downloaded from the TCGA Data Portal (https://tcga-data.nci.nih.gov/tcga/). Primary tumours with complete mRNA data $(n=333)$ were included. To examine the association of genes involved in DNA repair pathway and LDHA in TCGA cohort, log2 whole transcript mRNA expression values of each gene from downloaded process data (RNA Seq V2 
RSEM) were used as scatterplots. Pearson correlation coefficient was used to measure the linear correlation between LDHA and individual genes in DNA repair pathway.

3. SU2C/PCF Dream Team dataset consists of 150 metastatic samples derived from several anatomical locations, such as lymph node (42\%), bone (28.7\%), liver (12.7\%) and other soft tissues (16.7\%), using TruSeq RNA protocol (Illumina) [5]. The expression array data were downloaded from cBioPortal for cancer genomics under accession number dbGap: phs000915.v1.p1 (www.cbioportal.org/study?id=prad_su2c_2015\summary). Tumour samples with complete mRNA data $(n=118)$ were included. The mRNA expression of LDHA correlates with DNA repair genes in both MSKCC and TCGA datasets. We conducted an unbiased volcano plot analysis to examine the differential expressed transcript between mean high and low LDHA/BRCA1 in SU2C/PCF Dream Team cohort, using Plotly (https://plot.ly). Data were filtered based on processed total RNA from poly-A RNA sequencing data. In this cohort, gene expression were calculated as fragments per kilobase of exon per million fragments mapped (FPKM; normalised measure of gene expression), as published [15].

\section{Bioinformatics}

Tumour Mutational Burden (TMB): To calculate total mutational burden, we calculated the number of somatic, coding, base substitution, and indel mutations per megabase of the examined genome [6]. All base substitutions and indels in the coding region of targeted genes, including synonomous alterations, are initially counted before filtering as described below. Non-coding alterations were not counted. Alterations listed as known somatic alterations in COSMIC and truncations in tumor suppressor genes were not counted. This correction was performed to avoid upward skewing of mutational load, because FoundationOne preferentially profiles genes known to be recurrently mutated in cancer. Alterations predicted to be germline by the somatic-germlinezygosity algorithm were not counted. To calculate the mutation load per MB, the total number of mutations counted was divided by the coding region target territory, covering $1.09 \mathrm{MB}$ for the 124 genes.

Copy number alterations (CNA): To calculate copy number alterations (CNA), the total genomic territory spanned by gain, amplification, loss and deletion segments was summed and a percentage was generated using the size of the examined total genomic territory [7]. 

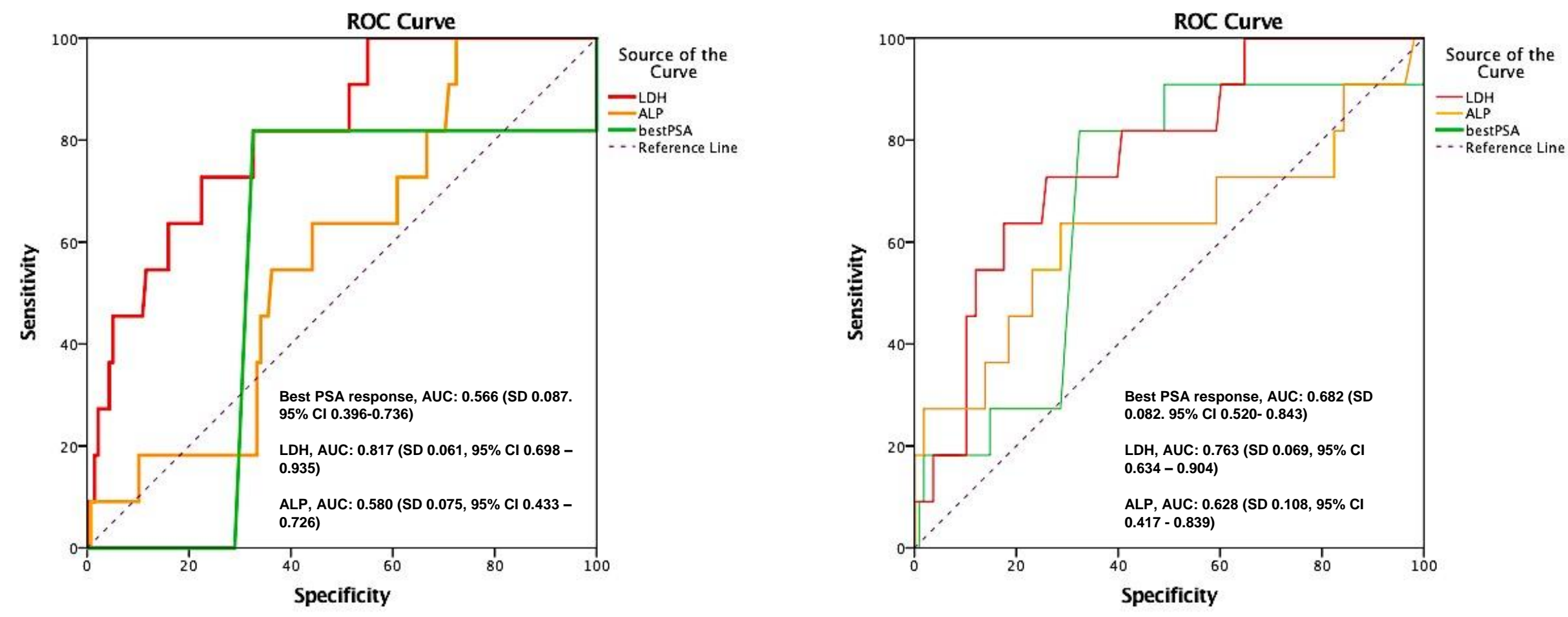

Supplementary Figure 1: LDH remains the best accurate tool for prognostic indicator, among ALP and Best PSA response in (A) training set, (B) test set of the Christie cohorts focusing on the endpoints of 3 months PFS. Best PSA response is defined as \% fall of PSA post 6 cycle of docetaxel. 


\begin{tabular}{|c|c|c|c|}
\hline \multirow[t]{2}{*}{ Characteristics } & \multicolumn{2}{|c|}{ Patients with available NGS data } & \multirow[t]{2}{*}{$P$ value } \\
\hline & High $(\geq 450)$ & Low $(<449)$ & \\
\hline Patients, n (\%) & 14 & 7 & NA \\
\hline $\begin{array}{l}\text { Age at initiation of } \\
\text { docetaxel, median (range) }\end{array}$ & $64(60-75)$ & $68(53-75)$ & 0.279 \\
\hline $\begin{array}{l}\text { PSA at initiation of } \\
\text { treatment, median (range) }\end{array}$ & $\begin{array}{c}409.1(74.1- \\
1789)\end{array}$ & $116.1(8-221.4)$ & $<0.001$ \\
\hline \multicolumn{4}{|l|}{ M stage } \\
\hline Bone only (M1b) & $11(78.6)$ & $5(71.4)$ & \multirow{4}{*}{0.771} \\
\hline LN only (M1a) & $0(0.0)$ & $0(0.0)$ & \\
\hline LN + Bone only (M1a/b) & $2(14.3)$ & $1(14.3)$ & \\
\hline $\begin{array}{l}\text { LN + Bone + visceral only } \\
\text { (M1a/b/c) }\end{array}$ & $1(7.1)$ & $1(14.3)$ & \\
\hline \multicolumn{4}{|l|}{ Best PSA response } \\
\hline $\begin{array}{l}\text { Partial responder } \\
(>50 \% \text { fall in PSA) }\end{array}$ & $2(14.3)$ & $4(57.1)$ & \multirow{3}{*}{0.094} \\
\hline $\begin{array}{l}\text { Stable disease } \\
(<49 \% \text { fall PSA })\end{array}$ & $6(42.9)$ & $2(28.6)$ & \\
\hline $\begin{array}{l}\text { Progressive disease } \\
\text { (any PSA rise) }\end{array}$ & $6(42.9)$ & $1(14.2)$ & \\
\hline \multicolumn{4}{|l|}{ Blood-based parameters } \\
\hline Haemoglobin & $11.4(8.8-13.1)$ & $11(9.7-13.5)$ & $<0.001$ \\
\hline ALP & $462(95-1451)$ & $263(112-540)$ & $<0.001$ \\
\hline Albumin & $45(36-51)$ & $42(36-44)$ & 0.26 \\
\hline
\end{tabular}

Supplementary Table 1: Baseline characteristics of patients with tissue available for NGS characterisation by Foundation Medicine. Age between high/low LDH groups were compared using Student's $t$ test; PSA level at initiation of docetaxel, haemoglobin, ALP and albumin was compared using the Wilcoxon rank-sum test; $M$ stage and Best PSA response was compared using Chi-square test. 


\begin{tabular}{|c|c|c|c|c|c|c|c|c|}
\hline & \multicolumn{4}{|c|}{ Univariate analysis } & \multicolumn{4}{|c|}{ Multivariate analysis } \\
\hline & \multicolumn{2}{|c|}{$\begin{array}{l}\text { Progression free survival } \\
\text { (PFS) }\end{array}$} & \multicolumn{2}{|c|}{ Overall Survival (OS) } & \multicolumn{2}{|c|}{$\begin{array}{l}\text { Progression free survival } \\
\text { (PFS) }\end{array}$} & \multicolumn{2}{|c|}{ Overall Survival (OS) } \\
\hline & $\mathrm{HR}(95 \% \mathrm{Cl})$ & $P$ value & $\mathrm{HR}(95 \% \mathrm{Cl})$ & $P$ value & $\mathrm{HR}(95 \% \mathrm{Cl})$ & $P$ value & $\mathrm{HR}(95 \% \mathrm{Cl})$ & $P$ value \\
\hline LDH (<450 vs. $>451)$ & $\begin{array}{l}0.535(0.366- \\
0.781)\end{array}$ & 0.001 & $\begin{array}{l}0.645(0.451- \\
0.921)\end{array}$ & 0.016 & $\begin{array}{l}0.598(0.401- \\
0.892)\end{array}$ & 0.012 & $\begin{array}{c}0.776(0.528- \\
1.140)\end{array}$ & 0.003 \\
\hline ALP & $\begin{array}{c}0.448(0.305- \\
0.698)\end{array}$ & 0.002 & $\begin{array}{c}0.410(0.304- \\
0.684)\end{array}$ & $<0.0001$ & $\begin{array}{l}0.545(0.389- \\
0.833)\end{array}$ & 0.038 & $\begin{array}{l}0.452(0.303- \\
0.691)\end{array}$ & 0.054 \\
\hline $\begin{array}{l}\text { PSA at initiation of } \\
\text { docetaxel }\end{array}$ & $\begin{array}{c}0.804(0.565- \\
1.145)\end{array}$ & 0.066 & $\begin{array}{c}0.620(0.422- \\
0.938)\end{array}$ & 0.139 & $\begin{array}{c}1.211(0.856- \\
1.701)\end{array}$ & 0.180 & $\begin{array}{l}0.701(0.501- \\
1.103)\end{array}$ & 0.201 \\
\hline $\mathrm{Hb}$ & $\begin{array}{l}0.825(0.731- \\
0.932)\end{array}$ & 0.002 & $\begin{array}{l}0.748(0.656- \\
0.853)\end{array}$ & 0.001 & $0.895(0.783-1.022)$ & 0.895 & $\begin{array}{l}0.806(0.699- \\
0.930)\end{array}$ & 0.197 \\
\hline Age & $\begin{array}{l}0.989(0.966- \\
1.012)\end{array}$ & 0.342 & $\begin{array}{l}0.995(0.972- \\
1.018)\end{array}$ & 0.654 & $0.996(0.973-1.019)$ & 0.996 & $\begin{array}{c}1.001(0.977- \\
1.026)\end{array}$ & 0.932 \\
\hline $\begin{array}{c}\text { PSA responder } \\
\text { (Any fall vs. Any } \\
\text { rise) }\end{array}$ & $\begin{array}{l}1.228(0.874- \\
1.727)\end{array}$ & 0.237 & $\begin{array}{l}0.643(0.456- \\
0.908)\end{array}$ & 0.012 & $0.827(0.577-1.184)$ & 0.299 & $\begin{array}{c}0.675(0.472- \\
0.964)\end{array}$ & 0.30 \\
\hline
\end{tabular}

Supplementary Table 2: 

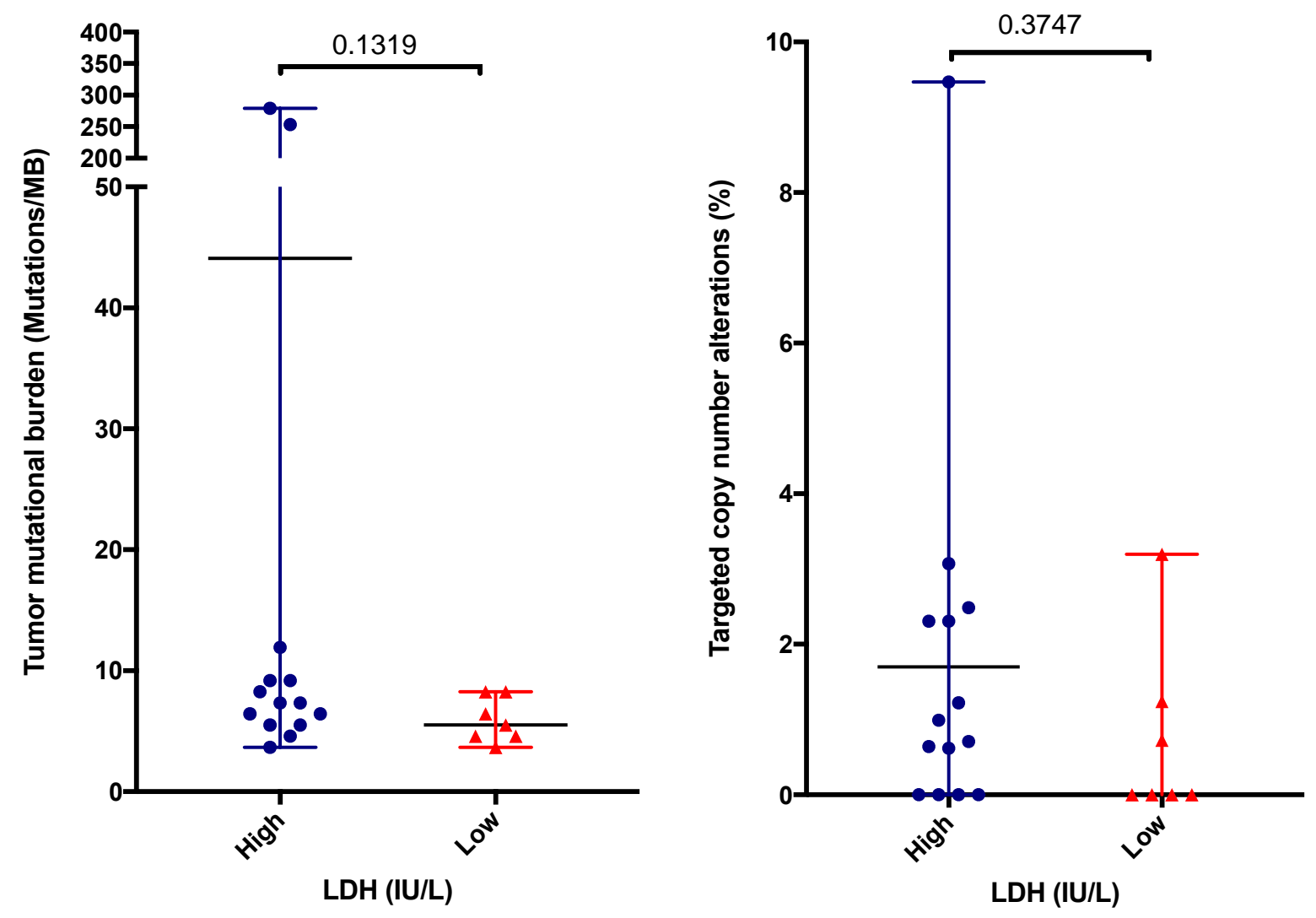

Supplementary Figure 2: Tumour Mutational Burden (TMB) and Copy Number Alteration (CNA) associated with patients with high and low LDH prior to docetaxel chemotherapy.

TMB (mean, 46.2 vs 6.2 mut/MB; Mann Whitney $p=0.1319$ ) and CNA (mean, 1.7\% vs $0.7 \%$; Mann Whitney $\mathrm{p}=0.3747$ ) in tumours from patient with high $\mathrm{LDH}(\mathrm{n}=14)$ and low LDH $(\mathrm{n}=7)$, dichotomised by $450 \mathrm{U} / \mathrm{L} \mathrm{LDH}$. 


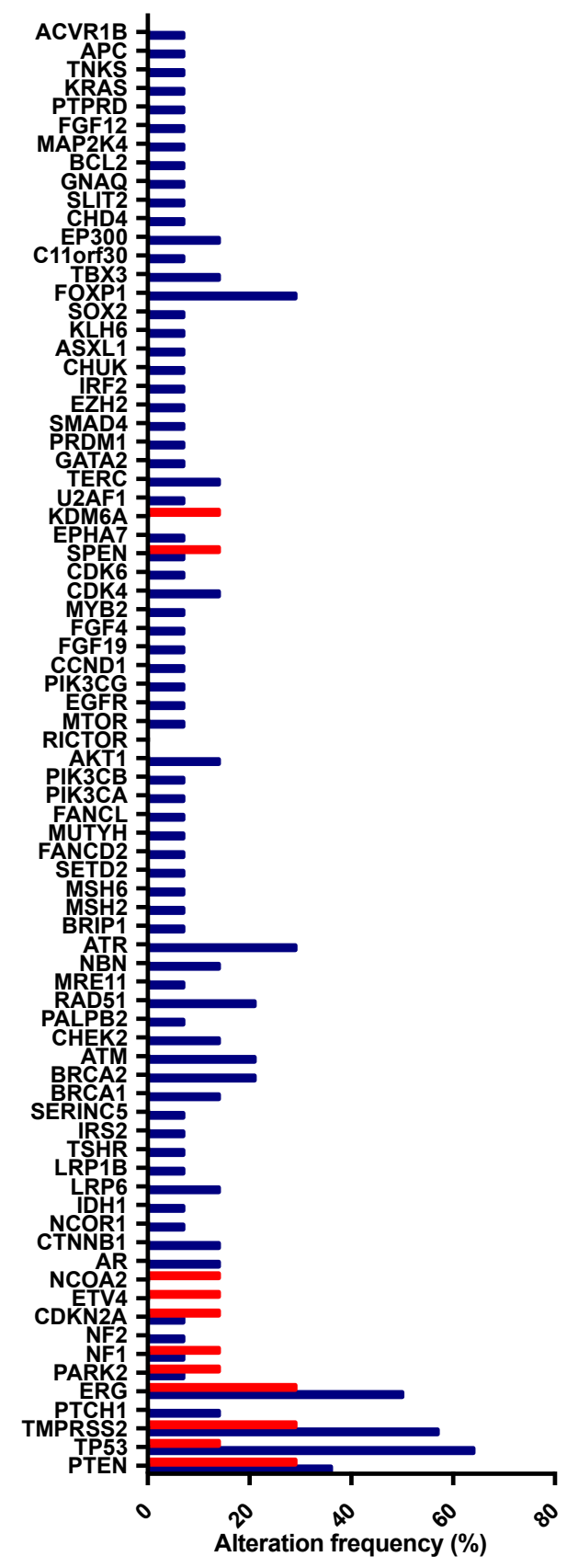

Supplementary Figure 3: Distribution of alteration counts in samples by high/low $\mathrm{LDH}$ in the contemporary cohort. For the panel, somatic mutations in the targeted sequenced genes were taken into account. The samples were subdivided into high (blue bar chart) or low (red bar chart) LDH. 

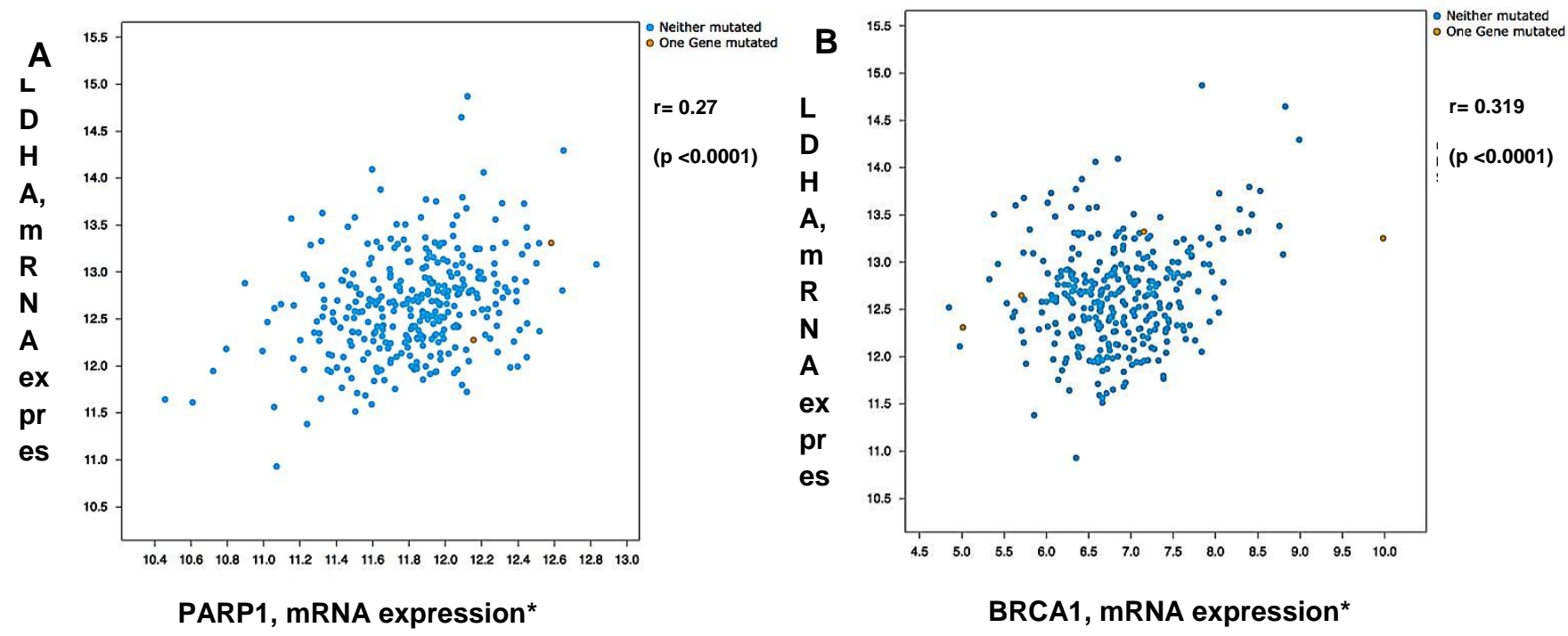

BRCA1, mRNA expression*
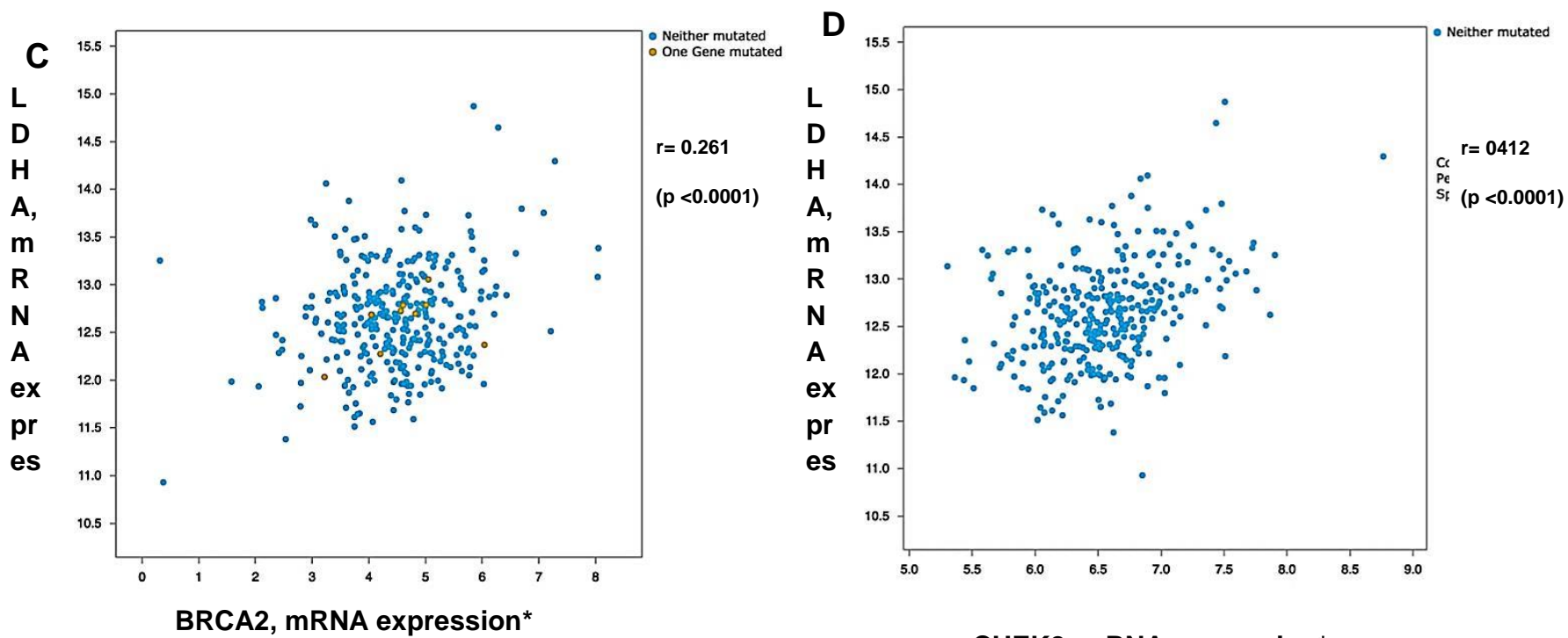

CHEK2, mRNA expression*

Supplementary Figure 4: Meta-analysis of the TCGA database shows a link between LDHA and DNA repair genes. Scatterplot analysis of normalised LDHA mRNA expression vs A) PARP1, B) BRCA1, C) BRCA2, D) CHEK2 mRNA expression. Expression shown as log2 whole transcript mRNA expression (Affymetrix Human Exon 1.0 ST arrays). Pearson correlation statistical analysis was used to compare the linear association of specific genes. 


\begin{tabular}{|c|c|c|c|c|}
\hline \multirow{2}{*}{$\begin{array}{l}\text { Common genes } \\
\text { rearranged in cancer } \\
\text { BRAF }\end{array}$} & \multicolumn{4}{|c|}{ Cancer related genes } \\
\hline & ABL1 & DDR2 & KRAS & RAD51 \\
\hline ETV1 & ABL2 & DICER1 & LRP1B & RB1 \\
\hline ETV4 & AKT1 & EIF4E & MAP3K1 & RBM10 \\
\hline MLL & AKT1S1 & EIF4EBP1 & MAPKAP1 & RHEB \\
\hline TEMPRSS2 & AKT3 & EPHB1 & MCL1 & RICTOR \\
\hline \multirow[t]{25}{*}{ ERG } & APC & ERBB3 & MDM2 & RNF43 \\
\hline & AR & ERBB4 & MDM4 & RPS6 \\
\hline & ARID1A & FANCL & MED12 & RPS6KB2 \\
\hline & ASXL1 & FGF12 & MET & RUNX1T1 \\
\hline & ATM & FGF19 & MLL2 & SDHD \\
\hline & ATR & FGF23 & MLST8 & SF3B1 \\
\hline & AXIN1 & FGF3 & MSH2 & SLIT2 \\
\hline & BCL2L2 & FGF4 & MTOR & SMAD4 \\
\hline & BCL6 & FGFR1 & MUTYH & SOX2 \\
\hline & BCOR & FGFR3 & MYC & SPEN \\
\hline & BRCA2 & FGFR4 & NBN & SPOP \\
\hline & BRIP1 & $\mathrm{FH}$ & NF2 & STAT3 \\
\hline & C11orf30 & FLT1 & PARK2 & TBX3 \\
\hline & CARD11 & FLT4 & PIK3C2B & TERC \\
\hline & CCND1 & FOXO3 & PIK3CA & TP53 \\
\hline & $\mathrm{CDH} 1$ & FOXP1 & PIK3CB & TSC1 \\
\hline & CDK12 & GATA2 & PIK3CG & TSC2 \\
\hline & CDK4 & GSK3B & PIK3R1 & TSHR \\
\hline & CDK6 & HGF & PREX2 & U2AF1 \\
\hline & CDKN1B & HRAS & PRKCl & VEGFA \\
\hline & CDKN2A & IL7R & PRKDC & VHL \\
\hline & CHEK2 & IRS2 & PRR5L & WISP3 \\
\hline & CREBBP & JAK1 & PTCH1 & ZNF703 \\
\hline & CTNNB1 & KDM6A & PTEN & \\
\hline & CUL3 & KLHL6 & PTPN11 & \\
\hline
\end{tabular}

Supplementary Table 3: Foundation Medicine ligation-based sequencing libraries representing 3167 exons of 118 cancer-related genes plus 18 introns of 6 genes often rearranged in cancer. 


\section{Supplementary References:}

1. Beltran $H$, Yelensky R, Frampton GM, Park K, Downing SR, MacDonald TY, Jarosz M, Lipson D, Tagawa ST, Nanus DM, Stephens PJ, Mosquera $\mathrm{JM}$, Cronin MT, Rubin MA, et al. Targeted next-generation sequencing of advanced prostate cancer identifies potential therapeutic targets and disease heterogeneity. 2013; 63(5): 920-6.

2. Frampton GM, Fichtenholtz A, Otto GA, Wang K, Downing SR, He J, et al. Development and validation of a clinical cancer genomic profiling test based on massively parallel DNA sequencing. Nat Biotech. 2013 11/print; 31(11):1023-31.

3. Taylor BS., Schultz N., Hieronymus H., Gopalan A., Xiao Y., Carver BS., Arora VK., Kaushik P., Cerami E., Reva B., Antipin Y., Mitsiades N., Landers T., Dolgalev I., Major JE., Wilson M., Socci ND., Lash AE., Heguy A., Eastham JA., Scher HI., Reuter VE., Scardino PT., Sander C., Sawyers CL., Gerald WL., Integrative Genomic Profiling of Human Prostate Cancer, Cancer Cell, Volume 18, Issue 1, 13 July 2010, Pages 11-22, ISSN 1535-6108.

4. Abeshouse A, Ahn J, Akbani R, Ally A, Amin S, Andry CD, et al. The Molecular Taxonomy of Primary Prostate Cancer. Cell. 2015; 163(4):1011-25.

5. Robinson D, Van Allen Eliezer M, Wu Y-M, Schultz N, Lonigro Robert J, Mosquera J-M, et al. Integrative Clinical Genomics of Advanced Prostate Cancer. Cell. 2015 5/21; 161(5):1215-28.

6. Chalmers ZR, Connelly CF, Fabrizio D, Gay L, Ali SM, Ennis R, Schrock A, Campbell B, Shlien A, Chmielecki J, Huang F, He Y, Sun J, Tabori U, Kennedy M, Lieber DS, Roels S, White J, Otto GA, Ross JS, Garraway L, Miller VA, Stephens PJ, Frampton GM. Analysis of 100,000 human cancer genomes reveals the landscape of tumor mutational burden. Genome Med. 2017 Apr 19;9(1):34.

7. Hieronymus, H., Schultz, N., Gopalan, A., Carver, B. S., Chang, M. T., Xiao, Y., Heguy A., Huberman K., Bernstein M., Assel M., Murali R., Vickers A., Scardino PT., Sander C., Reuter V., Taylor BS., Sawyers, C. L. (2014). Copy number alteration burden predicts prostate cancer relapse. Proceedings of the National Academy of Sciences of the United States of America, 111(30), 11139-11144. 
EUROPEAN UROLOGY Authorship Responsibility, Financial Disclosure, and Acknowledgment form.

By completing and signing this form, the corresponding author acknowledges and accepts full responsibility on behalf of all contributing authors, if any, regarding the statements on Authorship Responsibility, Financial Disclosure and Funding Support. Any box or line left empty will result in an incomplete submission and the manuscript will be returned to the author immediately.

Title

$\operatorname{Dr}$

First Name Mick

Middle Name David

Last Name Brown

Degree Ph.D. (Ph.D., M.D., Jr., etc.)

Primary Phone $\quad+441613060811$

(including

country code)

Fax Number

N/A

(including country code)

E-mail Address_ｍichael.d.brown@manchester.ac.uk

\section{Authorship Responsibility}

By signing this form and clicking the appropriate boxes, the corresponding author certifies that each author has met all criteria below (A, B, C, and D) and hereunder indicates each author's general and specific contributions by listing his or her name next to the relevant section.

$\bigotimes$ A. This corresponding author certifies that:

- the manuscript represents original and valid work and that neither this manuscript nor one with substantially similar content under my authorship has been published or is being considered for publication elsewhere, except as described in an attachment, and copies of closely related manuscripts are provided; and

- if requested, this corresponding author will provide the data or will cooperate fully in obtaining and providing the data on which the manuscript is based for examination by the editors or their assignees;

- every author has agreed to allow the corresponding author to serve as the primary correspondent with the editorial office, to review the edited typescript and proof.

$\bigotimes$ B. Each author has given final approval of the submitted manuscript. 
$\bigotimes$ C. Each author has participated sufficiently in the work to take public responsibility for all of the content.

$\bigotimes$ D. Each author qualifies for authorship by listing his or her name on the appropriate line of the categories of contributions listed below.

The authors listed below have made substantial contributions to the intellectual content of the paper in the various sections described below.

(list appropriate author next to each section - each author must be listed in at least 1 field. More than 1 author can be listed in each field.)

_ conception and design Brown, Clarke, Elliott

_ acquisition of data Hiew, Hart

_ analysis and interpretation of data Hiew, Brown, Clarke, Ali, Hart

_ drafting of the manuscript Hiew, Brown Clarke

_ critical revision of the manuscript for

important intellectual content

Brown, Clarke

_ statistical analysis

Hiew, Brown, Ali

_ obtaining funding

Clarke

_ administrative, technical, or

material support

Lau, Maddineni, Ramani, Sangar

_ supervision

Clarke, Brown

_ other (specify)

\section{Financial Disclosure}

$\bigotimes$ None of the contributing authors have any conflicts of interest, including specific financial interests and relationships and affiliations relevant to the subject matter or materials discussed in the manuscript.

OR 
$\square$ I certify that all conflicts of interest, including specific financial interests and relationships and affiliations relevant to the subject matter or materials discussed in the manuscript (eg, employment/ affiliation, grants or funding, consultancies, honoraria, stock ownership or options, expert testimony, royalties, or patents filed, received, or pending), are the following: (please list all conflict of interest with the relevant author's name):

\section{Funding Support and Role of the Sponsor}

$\bigotimes$ I certify that all funding, other financial support, and material support for this research and/or work are clearly identified in the manuscript.

The name of the organization or organizations which had a role in sponsoring the data and material in the study are also listed below:

All funding or other financial support, and material support for this research and/or work, if any, are clearly identified hereunder:

The specific role of the funding organization or sponsor is as follows:

Design and conduct of the study

Collection of the data

Management of the data

Analysis

Interpretation of the data

Preparation

Review

Approval of the manuscript

OR

$\bigotimes$ No funding or other financial support was received. 


\section{Acknowledgment Statement}

This corresponding author certifies that:

- all persons who have made substantial contributions to the work reported in this manuscript (eg, data collection, analysis, or writing or editing assistance) but who do not fulfill the authorship criteria are named with their specific contributions in an Acknowledgment in the manuscript.

- all persons named in the Acknowledgment have provided written permission to be named.

- if an Acknowledgment section is not included, no other persons have made substantial contributions to this manuscript.

M.D. Brown

After completing all the required fields above, this form must be uploaded with the manuscript and other required fields at the time of electronic submission. 


\section{MANCHESTER 1824}

The University of Manchester
Dr M.D. Brown Ph.D.

Genito Urinary Cancer Research Group

Manchester Cancer Research Building

Wilmslow Road

Manchester

M20 4GJ

UK

$+44(0) 1618060811$

michael.d.brown@manchester.ac.uk

Professors Gratzke and Catto

EUROPEAN UROLOGY FOCUS EDITORIAL OFFICE

Academic Urology Unit, University of Sheffi eld

The Medical School

Beech Hill Road

Sheffi eld S10 2RX, UK

E-mail: eufocus@europeanurology.com

Tel: +31 26389 0680; Fax: +441142712268

\section{Dear Professor Gratzke and Professor Catto}

Thank you for giving us the opportunity to transfer this manuscript entitled "Primary mutational landscape linked with pre-docetaxel LDH levels predicts docetaxel response in mCRPC" to European Urology Focus. We are grateful to the reviewers for their comments following our original submission to European Urology. We have endeavoured to address the issues raised as follows:

\section{Reviewer \#1:}

1. Has the study been approved by an ethical committee?

Response: The study was carried out with full ethical approval. We have added a statement to this effect in the main text at line 108

\section{$\underline{\text { Reviewer \#2: }}$}

1. The authors have not paid full attention to the Author instructions for European urology. For example, automatic page and line numbering have not been activated (these greatly facilitate the review process); double line spacing etc. Do please make a better effort to read the author instructions for manuscript preparation.

Response: We thank the reviewer for pointing this out. The format has been revised to reflect the author instructions

2. Abstract; results and limitations - it is and dated in the author instructions that limitations are also included in this section. Please do so

Response: We have stated that only 21 patients underwent NGS in this study in the main text (Line 206), 14 of which had $L D H \geq 450 \mathrm{U} / \mathrm{L}$ within the abstract (Line 64-65) and that the NGS findings were cross correlated through meta-analysis of the MSKCC and SUCF/PCF databases

3. It is striking how few patients in the M0 dataset who underwent surgery (5\%) as primary treatment, versus those who underwent RT (52\%) and even primary ADT in the M0 setting (38\%, odd management). Do the authors have any comments on this?

Response: We note the views of Reviewer\#2 in this regard. However, the majority of the patients who were M0 at diagnosis in our training and test sets were risk-stratified as "high-risk" based on D'Amico classification. Radiotherapy combined with ADT is currently a standard curative treatment for patients with this disease type, as is reflected in the EAU Prostate Cancer Guidelines (Section 
6.2.4). At the time of sampling most UK patients were treated in this way and indeed, in contemporary UK management of high risk localised disease most patients still receive radiotherapy and ADT as their standard of care (National Prostate Cancer Audit report 2017: www.npca.uk.com). As far as we are aware there is no level 1 evidence to show that treatment of high risk localised prostate cancer in this way is inferior to treatment with radical surgery.

Regarding the use of ADT monotherapy, evidence regarding benefit by combining this with local radiotherapy was not published until 2013 (Warde P et al J Clin Oncology 2013), predating our sample collection. The survival improvement from the combined therapy in that study was $8 \%$ and all of our patients in this analysis had failed treatment, developing metastases. We therefore feel that the differential treatment effect is likely to be negligible in the context of this study.

4. Were all primary biopsies done on prostate biopsy, or were some on metastases? Please comment

Response: All of the samples were taken from the primary prostate biopsies (Line 108-109).

5. Please explain how the training and test cohorts were selected. Please explain the rationale for this

Response: The training and test cohorts were dichotomised based on year of biopsy, pre and post 2006. As described in the manuscript the cohorts have broadly similar demographics and can therefore be described as matched.

6. Statistics - I defer to comments from statistical reviewer

Response: Statistical analysis was conducted by the lead and co-authors and all analyses were reviewed separately by a professional medical statistician (Hitesh Mistry): his contribution is highlighted in the acknowledgements.

7. The incidence of DRGs is extraordinarily high for what (I presume) is a primary biopsy cohort with no prior therapy. Please explain further; this is much higher than one would expect

Response: We thank the reviewer for this observation. However, we emphasise (Line 250) that this cohort of men were in late stage, with MCRPC and undergoing docetaxel therapy. They are therefore a selected group of patients with aggressive disease at the outset or with aggressive localised disease which had progressed with metastatic development. In this cohort type we would expect a higher incidence of DRGs in their primary biopsy. In support of this notion, the published literature shows that prostate cancer patients with DRGs reported ranges from 13\% (TCGA) to 40\% (SU2C/PCF), reflecting the stages of disease when the analysis was carried out. We feel that our patients, being late stage and all progressive would likely have a high rate of DRG disruption. In acknowledgment of this, we have added a line of explanation in the discussion section (Line 297-300).

8. Further, what was the incidence in the M0 vs M1 at presentation groups

Response: The incidence of M0 and M1 disease at presentation is presented in table 2. To further clarify this we have edited the table to highlight the number of patients within each cohort presenting with either M0 or M1 disease

\section{$\underline{\text { Reviewer\#3 }}$}

The cohort should be considered a classical cohort (2005-2012), i.e. pre-abi/enza and the overall survival is short. This is a limitation with respect to the clinical implication of CRPC AD 2018! This should be made clear I the discussion.

Response: We thank the reviewer for this observation, with which we agree completely. We have added a rider in the patients / methods section to highlight this (Line 107) and we have further emphasised this fact with an explanatory line in the discussion (Line 297-300).

Overall, the paper is not well written; 
It takes the reader (and the reviewer) a lot of effort to judge the significance of the results Eg Table $4 \mathrm{LDH}$ cut of in training and tests sets; the sens and spec in the test cohort is much lower; when AUC's are compared, how are $95 \%$ CIs?

Genomic changes; TMB and CAN have a p-value > p.05, i.e. not significantly different.

Response: We thank the reviewer for this helpful observation and agree that both the TMB and CAN do not reach $95 \%$ confidence limit $(\mathbf{P}<\mathbf{0 . 0 5})$. However, there is a trend towards an increase in both in mCRPC patients with high serum LDH levels. We have not overstated these finding in the manuscript. We would also plead in mitigation that a topic of this complexity can be "dense" and take time to read. However, we maintain that it is important to add in detail to facilitate understanding of the message conveyed. We hope that this does not detract from the main focus of the manuscript and the resulting discussion ie: that high LDH predicts poor response to docetaxel in the mCRPC setting and that mutations, particularly within the DNA repair pathway found within the primary biopsy of this associated phenotype.

Fig 1. AUCs; are these of the combined cohort? If so that is not justified, training and test should be plotted separately.

Response: We acknowledge that the AUC in figure 1 relates to the combined cohort (Line 163). However, the AUCs for both the training and test cohorts were supplied as figure 1 in the supplementary material. We have added words to the text to direct the reader (Line 169).

These are just a few of the unclarities in the paper; In this large cohort only few tumors were molecularly classified. Again a significant limitation of the paper

Response: We agree with reviewer 3 that a limitation of this study was the small numbers of patients with sufficient tissue available for genomic analysis. This is, in part, because of the prohibitively costly nature of undertaking genomic sequencing of this nature in such patient cohorts, and more importantly, the paucity of patient cohorts with matched primary biopsies internationally with follow up to death and fully annotated treatment outcome throughout their disease journey. To mitigate this fact and strengthen our hypothesis and conclusions undertook a meta-analysis of the larger TCGA (333 localised prostatectomies), SU2C/PCF (150 mCRPC biopsies) and MSKCC (181 localised prostatectomies) cohorts. These demonstrated that the link between genomic abnormalities within the DNA repair pathway, subsequent high $\mathrm{LDH}$ in the $\mathrm{mCRPC}$ setting and the poor response to docetaxel treatment. We feel this consistency with our primary biopsy results is sufficiently strong for us to draw our conclusions as set out in the manuscript.

We hope that our responses to the helpful comments and observations of the reviewers have been comprehensive and satisfactory. We thank you again for reconsidering this manuscript for publication in European Urology Focus.

Yours faithfully

Dr M. Brown PhD

Research Fellow

GUCR Group 
Consultant Urological Surgeon

Professor of Urological Oncology

The Christie and Salford Royal Hospitals

Manchester UK 